\title{
"Squeeze and Lift": A Design Ethnography of Learning and Teaching Pelvic Floor Exercises
}

\author{
By \\ Ruth Emma Barnard \\ Victoria University of Wellington
}

July 2017

A thesis submitted to the Victoria University of Wellington in fulfilment of the requirements for the degree of Master of Design 


\title{
A DESIGN ETHNOGRAPHY OF PELVIC FLOOR EXERCISES
}

\begin{abstract}
Pelvic floor exercises are an important practice in the prevention and resolution of pelvic floor disorder. However, pelvic floor exercises are often not practiced regularly or correctly which puts women at high risk of experiencing pelvic floor disorder symptoms. These symptoms are debilitating in terms of physical and mental health, and when ignored can worsen over time. In particular, pregnant and postnatal women are at the most risk of this disorder and still do not practice the exercises as required. This study identifies the lack of correct and regular exercises being practiced as a complex social and cultural issue which is best explored with ethnographic design research. The use of semi structured interviews, narrative analysis and informational probes enabled an open ended exploration of pregnant and postnatal women's experiences with learning and practicing pelvic floor exercises. Health professionals experience with teaching pelvic floor exercises has also been explored and findings have shown that to assist regular and correct exercise there is a need for professional diagnosis and guidance, suitable to each women's health, lifestyle, and way of learning. Themes in the findings included; Safety and Professional Support, Teaching PFX with Metaphor, Integrating PFX into Daily Life and Device Concerns and Feedback. Design recommendations which correspond to each of these themes were formed. Discussion of these findings using background literature also gave crucial context to this study, underscoring overarching key themes of education and empowerment which future pelvic floor exercise designs should embrace. Finally, this study addresses the strengths and weaknesses of an ethnographic design research approach in informing the development of future designs and systems for healthcare, and opens spaces for future work.
\end{abstract}

Keywords: Design ethnography, PFX, design development. 


\section{A DESIGN ETHNOGRAPHY OF PELVIC FLOOR EXERCISES}

\section{Acknowledgements}

Firstly, I give my thanks to the Centre of Research Excellence in Medical Technologies (CoRE MedTech) in New Zealand and Victoria University School of Design (VUW) in Wellington for granting me a scholarship which supported the completion of this paper. Thank you to Dr Catherine Caudwell who bought the opportunity of applying for this scholarship to my attention. I've also been lucky enough to have Dr Caudwell as my supervisor who has given scholarly guidance and friendly encouragement throughout this thesis. I want to thank Dr Edgar Rodriguez for his support as the Smart Interactions team leader and as my supervisor. Dr Rodriguez has lead team meetings which have not only been constructive but have shaped my experience with writing a Master's thesis in a truly positive way. I would also like to thank my third supervisor, Viv Baartman, Head of Design and Experience at Davanti Consulting, whose generous commitment to this project has given a professional perspective. Meetings with Viv always strengthened my motivation to use this research to truly make a positive change for women.

This brings me to the respondents, their input is what this whole thesis is about, and it truly would not have been possible without them. The health professionals and women in this study not only gave their time but did so with great interest and enthusiasm, for this I thank them.

I would like to thank my partner, David Harris, his ceaseless support goes above and beyond what anyone could hope for, thank you for everything. My whole hearted thanks also go to my Dad, Tim Barnard and my Mum, Wendy Pembleton for their financial support through the vast majority of my education. I also want to thank them and my brother Matthew for being an endless source of much needed humour and motivation. And finally, I give my thanks to Wilbur who has taught me more than he knows. 


\section{TABLE OF CONTENTS}

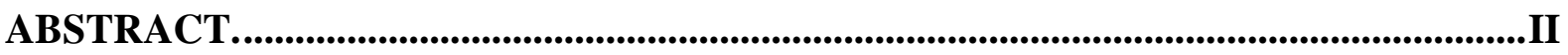

ACKNOWLEDGEMENTS. ................................................................................................ III

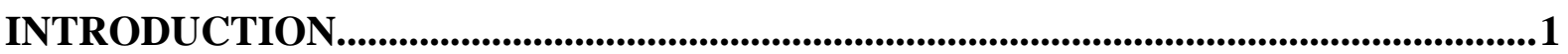

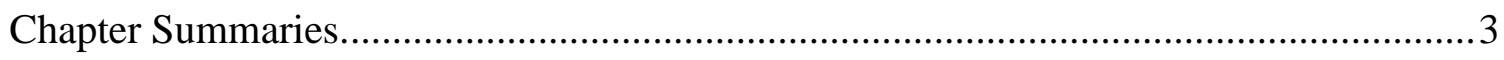

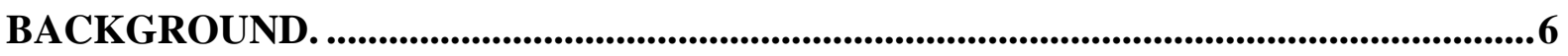

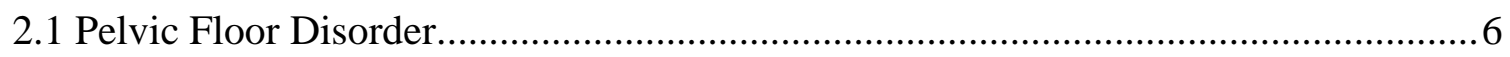

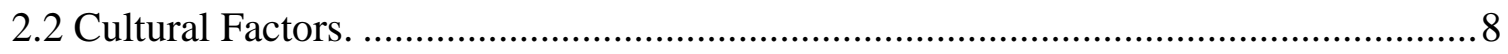

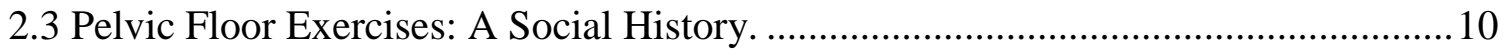

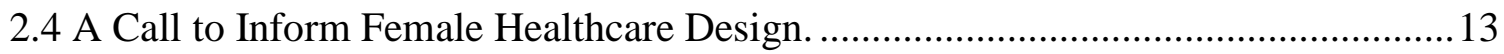

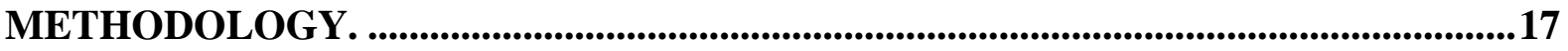

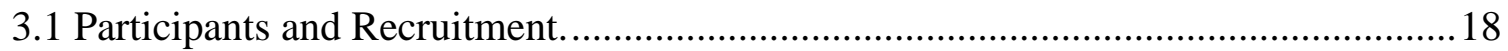

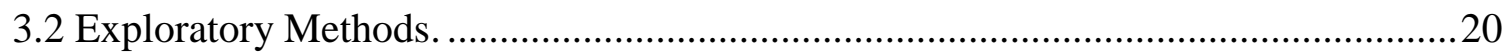

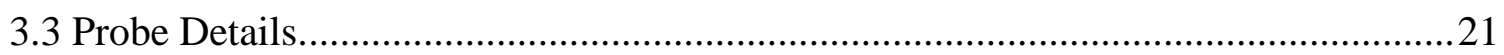

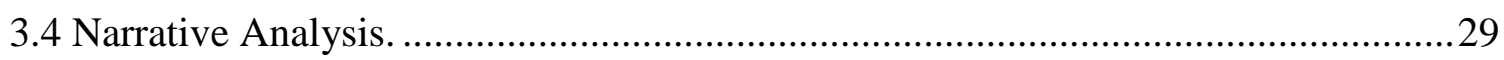

FINDINGS AND DESIGN RECOMMENDATIONS...............................................32

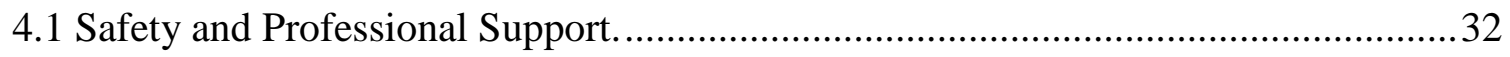

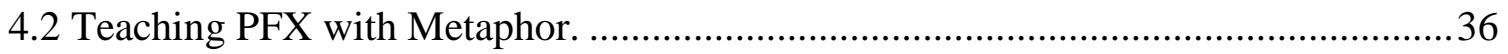

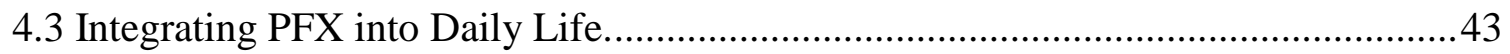

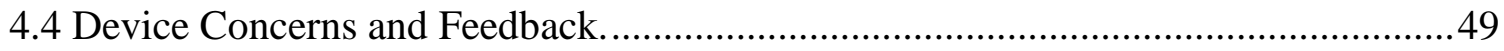

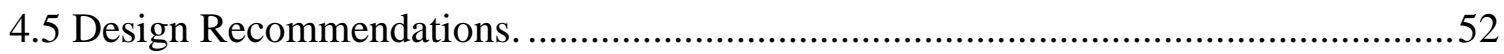

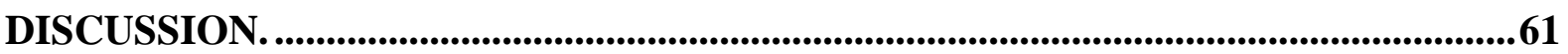

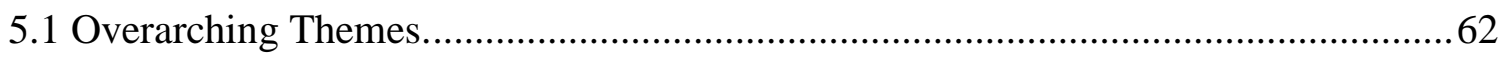

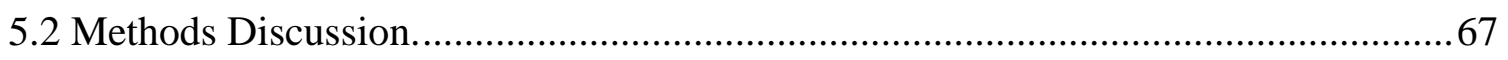

5.3 Design Ethnography Research; Lessons Learned. ................................................ 70

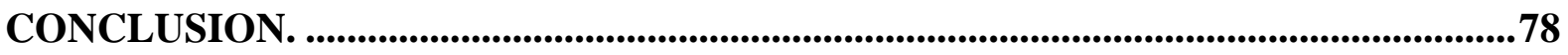

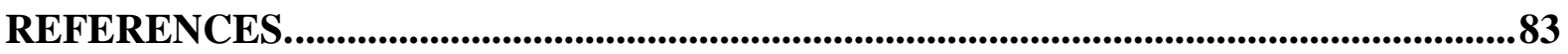




\section{Introduction}

One cannot understand the problem without knowing about its context.

(Rittel \& Webber, 1973, p. 162)

When a woman has pelvic floor disorder (PFD) it negatively impacts her daily life both physically and mentally. Pelvic floor exercises (PFX) have been shown to prevent and resolve pelvic floor disorder symptoms (Boyle et al 2012; Moossdorff-Steinhauser., 2015; Dawood, Jackson, \& Price, 2010). Despite this, women do not conduct the required amount of PFX during pregnancy and after giving birth and are often conducting exercises incorrectly (Mason et al, 2010, Moossdorff-Steinhauser et al, 2015; Lagro-Janssen, 2012). The pelvic floor is understood as a complex group of muscles, membrane and bone supporting the pelvic cavity (DeLancey \& Wei , 2008, p. 4). Consequently, it follows that PFD in women is physically complex with a variety of symptoms including urinary incontinence symptoms, pelvic organ prolapse (POP), and pelvic pain (Haylen et al 2009, p.7). In combination with the physical limitations that these symptoms cause, women with PFD have also reported feelings of frustration, poor emotional health, embarrassment and shame (Porrett, 2010, para 3.2.2). Pregnant and postnatal women have an increased risk of developing these symptoms as pregnancy and childbirth are one of the major stressors on the pelvic floor (De Lancey \& Wei, 2008, p. 3; Moossdorff-Steinhauser, 2015, p182-3; Rortveit et al 2003).

A large New Zealand based project seeks to address the issue of the lack of exercises being conducted by developing a PFX facilitating app and insertable device, currently called R-leaf. This project is being conducted by the University of Otago, Victoria University of Wellington's Design school and the Centre of Research Excellence in Medical Technologies (CoRE MedTech). Through ethnographic design research this thesis seeks to inform the future development of this device and the future development of similar devices, designs and 
A DESIGN ETHNOGRAPHY OF PELVIC FLOOR EXERCISES

systems which aim to facilitate women with regular and correct PFX. Firstly, this paper has identified the issue of lack of correct and regular PFX as a social, cultural and emotional issue or as coined by Rittel and Webber, a "wicked problem" (1973, p 160-169). Lack of regular and correct exercises is tied not only to the individual but to education, healthcare and more generally social beliefs and culture (Kenton \& Mueller, 2006; Almeida \& Arrigoni, 2014). Overtime, treatment for this disorder has developed synonymously with the turbulent progression of female healthcare and female health equality. Prior to the $20^{\text {th }}$ century women were commonly socially demoralised and rejected when struggling with incontinence, this began to change following the Second World War (Gordon, 2014, p.19-21). Since 1950 insertable pelvic floor feedback devices have been recommended to women to offer internal resistance for PFX and to show if exercises are being completed correctly (Kegel, 1948).

The purpose of my project is to explore the experiences of pregnant and postnatal women and health professionals with learning, teaching or practicing PFX and to use this exploration to inform the future development of PFX devices. Ethnographic design research is used to explore emotional and social experiences in context which has enabled rich data and holistic outcomes to inform and inspire design (Nova, 2014, p. 34; Dijk, 2010). Methods such as semi structured interviews, informational probes, and narrative analysis are employed. Outcomes include, design recommendations, findings and background literature, which are used to ultimately discuss the overarching themes and how this research can inform the development of future PFX designs. The demographic focus is women in their 20's or 30's who are pregnant or postnatal and live in New Zealand. Women and health professionals were chosen for the study through purposive sampling and the snowballing method (Schutt 2012, p157-8). Subsequently, this research addresses a need for application of human centred research for healthcare design (Crabtree et al, 2003, p1; Hirsch et al et al, 2000, p 
A DESIGN ETHNOGRAPHY OF PELVIC FLOOR EXERCISES

2; Savage, 2000) which extends into female healthcare design (Xue, 2009; Marques,Stothers \&Macnab, 2010). Strengths and weaknesses of the application of this specific approach are discussed and spaces for future work are illuminated.

\section{Chapter Summaries}

\section{Background}

In this background section I highlight that pregnant and postnatal women are required to practice PFX, which has been shown to prevent or alleviate PFD. The health and social issues that PFD causes are discussed here. Despite the need, the majority of women do not practice regular or correct PFX, this is identified in this chapter to be a cultural and social issue which is best addressed through a human centred research approach. In examination of a brief social history of female healthcare and human centred research for female healthcare I explain that there is importance in addressing further work in these areas. This chapter concludes with a discussion of human focused research for female healthcare design, and identifies design ethnography research as central to this study. Throughout this paper there is a focus on how the experiences of women and health professionals can inform the future development of designs for PFX. This study also addresses the role of design ethnography research in informing future healthcare designs. 
A DESIGN ETHNOGRAPHY OF PELVIC FLOOR EXERCISES

Methodology

This chapter discusses the modes of recruitment and demographic and details how design ethnography research will be conducted in the fieldwork and analysis. It is also shows that semi structured interviews and cultural probes can be employed to openly explore how PFX is taught, learnt and practiced. The lack of methodological guidance in this relatively new field is referenced. Additionally, the approaches taken to shape methods to suit this study are detailed here.

\section{Findings and Design Recommendations}

This chapter describes four key themes found from the probes and interview responses, and discusses these themes with reference to the transcriptions and relevant texts. The key findings are titled; Safety and Professional Support, Teaching PFX with Metaphor, Integrating PFX into Daily Life and Device Concerns and Feedback. A design recommendations list is presented in this chapter detailing key areas to be addressed in the development of future PFX devices and systems.

\section{Discussion}

The Discussion explains the findings and design recommendations of this study in the context of previous relevant literature. This illustrates two significant themes of education and empowerment. These themes show that design ethnography research exploring experiences of individuals can inform the future development of PFX designs on a micro and 
A DESIGN ETHNOGRAPHY OF PELVIC FLOOR EXERCISES

macro scale. The discussion also addresses the effect of specific tools used in the informational probes and highlights the strengths and weaknesses of this initial exploratory research.

\section{Conclusion}

This chapter illuminates that initial ethnographic design research adopts an open and exploratory approach which can prompt insightful discussion about experiences. I highlight the key outcomes of this research and explain that they can be used to provoke thought and further questions to guide design development and research. I also emphasise the need for a continued focus on cultural and social implications for future devices. 
A DESIGN ETHNOGRAPHY OF PELVIC FLOOR EXERCISES

\section{Background}

This project seeks to inform the development of future pelvic floor exercise (PFX) assisting systems for pregnant and postnatal women by exploring the experiences that women and health professionals have with PFX. Awareness and knowledge women have of PFX has been discussed to be limited and ineffective and positive social change for female healthcare in the $21^{\text {st }}$ century has been turbulent. However, there is a call for female healthcare designs to be developed with an understanding of women's experiences. This chapter describes the symptoms and causes of pelvic floor disorder as well as demonstrating that the lack of PFX is a complex cultural issue. This chapter also highlights that in order to inform the development of future PFX devices this issue should be addressed with ethnographic design research.

\subsection{Pelvic Floor Disorder}

The pelvic floor is often described as the "levator ani group of muscles" which means the muscles between the "pelvic peritoneum and the vulvar skin" (De Lancey \& Wei, 2008, p. 4). The term pelvic floor has also been used broadly to include all the "structures supporting the pelvic cavity" rather than a specific group of muscles and is understood as a complex group of muscles, membrane and bone (DeLancey \& Wei , 2008, p. 4). It supports the bladder, uterus, vagina/sexual tract and bowel/rectum helping these organs to function. This illustrates that the pelvic floor is a key part of the core of the body and its purpose is not only complex but crucial for overall health.

Literature has shown that pregnancy and childbirth are the major stressors on the pelvic floor alongside ageing (De Lancey \& Wei, 2008, p 3). It has also been described that 
A DESIGN ETHNOGRAPHY OF PELVIC FLOOR EXERCISES

there are a wide variety of reasons why women may have pelvic floor issues including; overactive muscles (Bower 2008), neurological disorder (Sigurdardottir, Steingrimsdottir, Arnason \& B $\varnothing$ 2011), and other changes in the body such as hormonal balance or systematic disease (Brubaker, 2008).

Pelvic floor muscles (PFM) can become ineffective in many ways and result in a variety of symptoms with varying severity. Knowledge of the variety of symptoms has space to be developed further (Haylen et al, 2009). Haylen et al have assembled a list of symptoms as reported by women with PFD or by caregivers (2009). The symptoms have many variations but are divided into; urinary incontinence symptoms, bladder storage symptoms, sensory symptoms (including, feeling the need to urinate despite being empty), voiding or post micturition symptoms (issues while urinating), pelvic organ prolapse symptoms (POP), symptoms of sexual dysfunction, symptoms of anorectal dysfunction, lower urinary tract pain or other pelvic pain and lower urinary tract infection (Haylen, et al, 2009, p. 7). This list exemplifies some of the symptoms showing how physically complex the disorder is.

In combination with the physical limitations that these debilitating symptoms cause, women with PFD have also reported feelings of frustration, poor emotional health, embarrassment and shame (Porrett, 2010, para 3.2.2). Isolation is also felt by women as symptoms can disable individuals from sexual interaction or cause them to avoid social events, travel or physical activities. However, PFX has been shown to prevent, alleviate or resolve PFD symptoms (Boyle et al 2012; Moossdorff-Steinhauser, 2015; Dawood, Jackson \& Price, 2010). Despite this, these exercises are rarely adhered to (Moossdorff-Steinhauser., 2015) or conducted correctly (Mason, 2010; Lagro-Janssen, 2012, p 410). I will expand on this issue below with a focus on pre and postnatal women. 
A DESIGN ETHNOGRAPHY OF PELVIC FLOOR EXERCISES

\subsection{Cultural Factors}

In order to narrow the focus demographic for this project a specific group which would be at the most danger of a weaker pelvic floor had to be chosen. The larger project which is engaged in developing a PFX device has a demographic focus of women in the pre or postnatal stage in their 20 's - 30's. It follows that my study also takes on this demographic focus. Literature has highlighted that pregnancy and childbirth are major stressors on the pelvic floor (De Lancey \& Wei, 2008, p. 3; Moossdorff-Steinhauser, 2015, p182-3; Rortveit et al 2003). During pregnancy and the postnatal period PFX are the most common form of treatment for any PFD symptoms, as drugs and surgery may be withheld; for example surgery is often not conducted until the woman has "completed her family" (Boyle et al 2012, p.3).

Pregnant and postnatal women are recommended to do PFX several times a day; they can be given training and guidance by a health professional such as a physiotherapist (Boyle et al, 2012, p.1). Professional assessment of the PFM (Pelvic Floor Muscles) can aid in a treatment plan and also shape the PFX recommendations given (Parkin, 2012, p.16). Pre and postnatal women are required to conduct PFX before and after childbirth, this has been shown to help to prevent symptoms such as incontinence as well as clear or alleviate PFD symptoms (Boyle et al 2012; Moossdorff-Steinhauser., 2015; Dawood, Jackson, \& Price, 2010). However, it was found in a study trial by Mason et al that women did not attend the required amount of PFX classes during and after birth and were also often conducting exercises incorrectly (Mason et al, 2010). It's also been shown that women often do not know how to practice exercises correctly, and more guidance and support is required (LagroJanssen, 2012, p 410).

The lack of preventative exercises being conducted as required is a cultural issue and 
A DESIGN ETHNOGRAPHY OF PELVIC FLOOR EXERCISES

could be more clearly described as a 'wicked problem'. A wicked problem is a problem that is unsolvable, it is a complex social, cultural and emotional issue which has many merging facets making it 'wicked' (Rittel \&Webber, 1973, p.158-169).

Women's individual decisions and understandings regarding PFD and PFX are intertwined with culture and context (Kenton \& Mueller, 2006; Almeida \& Arrigoni, 2014). For example urinary incontinence affects more women than diabetes, hypertension and osteoporosis, but it is the least likely disorder to receive treatment for (Kenton \& Mueller, 2006, Urinary Incontinence para 4). This lack of treatment illuminates further larger issues surrounding PFD. Additionally further awareness of PFD treatment for patients and physicians is needed (Kenton \& Mueller, 2006; Almeida \& Arrigoni, 2014). More specifically, it's highlighted that pre and postnatal women are in need of a new proactive approach including instruction and motivation from health professionals to aid women in completing regular PFX (Mason et al, 2010, Lagro-Janssen, 2012). Moossdorff-Steinhauser examined women's perspectives in a web based survey and found that " $95 \%$ of postpartum women want professional information on prevention of - later onset - PFD and acknowledge that supervised (PFX) peripartum is very important to prevent PFD” (Moossdorff-Steinhauser et al, 2015, p.186).

It's also described that pregnant and postnatal women's barriers to seeking support for their pelvic floor are related to their own and nurse practitioners beliefs about PFD which may create further stigma and normalisation of the issue (Porrett, 2012, p. 30). The awkwardness of discussion of PFX has been alluded to also, it's explained that there were levels of embarrassment in engaging in discussion about PFX with women (Almeida \& Arrigoni, 2014). This shows that barriers to exercises that pregnant and postnatal women face 
A DESIGN ETHNOGRAPHY OF PELVIC FLOOR EXERCISES

are bound to social and cultural contexts. Above it's shown that there are a variety of factors including lack of education, normalisation stigma and embarrassment that may delay women from seeking help.

Overall, women's attitudes to seeking help and the barriers women face in practicing or even discussing PFX today are deeply rooted in society and culture. This is a wicked problem as the issues individuals face are bound to deeper rooted cultural and social influences including problems in education and healthcare. Below, I will expand on this further as I discuss a social history illustrating the synonymous relationship between cultural context and female healthcare experiences. I also explain that promotion and understanding of the importance of PFX for women is relatively new.

\subsection{Pelvic Floor Exercises: A Social History}

In this section, the emergence of PFX and pelvic floor technologies is discussed alongside their social background. Preventative measures and cures for the symptoms of PFD exist in ancient history, although recorded documentation of PFX devices and promotion of pelvic exercise didn't begin until the $20^{\text {th }}$ century (Haslem, 2007; Dawood et al, 2010). By the 1930's-40's PFX had become better known and Kegel was promoting the use of a PFX device (Kegel 1948). By examining the social context leading up to this stage we can start to see how women's experience of their pelvic floor health was tied to social context.

The first sign of pelvic exercises arose in 1936. Margaret Morris, a dancer and choreographer from Scotland, stated that the tensing and relaxing of the pelvic floor muscles was a vital treatment and preventative for urinary and faecal incontinence. Margaret Morris's 
A DESIGN ETHNOGRAPHY OF PELVIC FLOOR EXERCISES

book; Maternity and Post Operative Exercises introduced the practice of pelvic exercises to the physiotherapy profession (Morris 1936 cited in Dawood et al 2010). This advancement could be connected with the move toward gender equality that came following World War Two. Pre-war there was a distinct stigma around female incontinence, a PFD symptom. For example Gordon highlights that women had often been socially demoralised and rejected when struggling with incontinence prior to the $20^{\text {th }}$ century $(2014$, p.19-21). However, a change was beginning to emerge in this era as many men from the Second World War had incontinence issues due to spinal cord injuries which altered social myths surrounding incontinence for both genders (Gordon, 2014, p.19-21).

It wasn't until after the Second World War that PFX as a urinary incontinence treatment became widespread (Siegel, 2016; Dawood et al 2010). In 1948, Arthur Kegel, a professor of obstetrics and gynaecology in America wrote that a program of PFX must include muscle education, feedback, resistance, and progressive intensity (1948). He underscored the need for consistent training completed with a perineometer, which is a device inserted into the vagina, he specified that this device must offer resistance so it can be squeezed against and also biofeedback which shows if exercises are being done properly (Kegel, 1948). Since 1950 PFX have been recommended for PFD with Kegel generating further interest on the internal anatomy of the pelvic floor. In years preceding this, the term “kegel exercises" has become a popular term for PFX (Dawood et al, 2010). The 70's and 80 's was a time in which female health activists in New Zealand paid close attention to issues such as “women's interactions with doctors, contraception, abortion, birth, violence, and breast and cervical cancer" (Cook, 2011, p7). There was a strong belief that women should have the freedom to understand their own bodies and health needs (Cook, 2011). 
A DESIGN ETHNOGRAPHY OF PELVIC FLOOR EXERCISES

The majority of medical research was conducted on men which feminist health activists stated as being a harmful lack of knowledge negatively affecting female healthcare (Cook, 2011). Subsequently, Highmore (2002) postulates that the driving force of feminism in the 1970's and 80's was that it was immersed in everyday life (p.28). All aspects of daily life such as "domestic routines" and "sexual identity" are described to be brought into question (Highmore, 2002, p.28), and in this example female healthcare can be added to that list. Shotwell and Grace (2016) describe that one of the main understandings of the goals of female health activism was that only by "controlling the terms of their own reproduction, mental and physical health, and healthcare could women achieve true equality and autonomy" (p.3). This shows that existing norms in healthcare were being challenged and it was through the everyday actions of individual women that larger social change was addressed. Despite the push for female health equality in the 70's and 80 's, by the 90 's the weight of this deep rooted issue was felt and the focus on female health dimmed (Cook 2011). The strong waves of activism from the 80's sent ripples into the 1990's and still influences today's healthcare. However, in New Zealand woman's health was absorbed by family and reproductive health (Shotwell \& Grace, 2016, p.1; Cook 2011). Female health activists sought to enable women to gain more knowledge about their bodies, have better interactions with clinicians and more effective female focused technologies and treatments (Cook, 2011).

Female health designs, systems and care have historically been shaped by cultural and social context which implicated in neglect and poor health for women (Gordon, 2014, p. 7-8, Cook, 2011, Parkin, 2012). In acknowledging this history it follows that if we are to design anything to assist women there is a need to first understand the experiences of women today (Xue, 2009). 
A DESIGN ETHNOGRAPHY OF PELVIC FLOOR EXERCISES

\subsection{A Call to Inform Female Healthcare Design}

Against this background of female healthcare, the call to address social, emotional and cultural issues that affect women's pelvic floor health is reinforced (Kenton \& Mueller 2006; Parkin 2012). This research seeks to inform the development of future PFX assisting systems so that they can be developed with awareness and sensitivity to the context and lives they seek to aid. Similar studies that use human centred research to inform healthcare designs reinforce this argument and illuminate a need for further design research for healthcare more generally (Crabtree et al 2011, p1; Xue, 2009; Hirsch et al, 2000, p 2).

Women often find it hard to practice pelvic floor exercises without initial supervision, guidance and feedback; today this is done through one on one sessions with physiotherapists and/or PFX devices with biofeedback abilities (Parkin 2012, p. 26). Female healthcare devices in general are described to be targeted at women who require monitoring, education and support (Xue, 2009). More specifically, pregnant and postnatal women have been shown to be interested in using devices for health, information and monitoring (Roudsari 2006; Millard \& Fintak 2002 as cited in Xue, 2009, p.15). There are apps for pregnant and postnatal women; The Pelvic Floor First website for example has information for women and a free downloadable app to help pregnant and postnatal women with their PFX (2016).

There are also many devices for women in general which utilise an app and a connected wireless device such as PeriCoach (2016) the LOOP (2015) and Elvie (20142017). These devices offer interaction with the screen via an insertable device that monitors your internal movements. For example Elvie (Elvie, 2014-2017) is a device inserted into the vagina and connected remotely to your app via Bluetooth. It includes game centred activities to aid completion of pelvic exercises; for example by squeezing your pelvic floor muscles a 
A DESIGN ETHNOGRAPHY OF PELVIC FLOOR EXERCISES

geographic circular shape moves up and down on the interface. Your aim as the player is to get this shape to hit moving targets that travel across the screen. The Elvie website also indicates that it is possible to use this device during pregnancy (Elvie, 2014-2017).

The number and variety of devices and technologies available to aid women with PFX has rapidly increased in the $21^{\text {st }}$ century. However the issue of women not practicing exercises still persists and how to aid these women is a complex question (Marques, Stothers \& Macnab, 2010; Kenton \& Mueller 2006; Lagro-Janssen, 2012). As these devices seek to aid this issue they must be designed with an awareness of the experiences and perceptions of women. The need for a human focused research approach in health technology design for women is reinforced by Xue who describes that there is a need to for female health design to break away from a history of unequal health treatment (Xue, 2009). The majority of medical device designs for women focus on the innovative application of technologies, materials and manufacturing and there is limited research that puts women at its centre which can result in uncomfortable, stigmatised designs that become a barrier to wellbeing (Xue, 2009, p. 48). Seeking to understand women's experiences with health and healthcare in early stages of design can give developing designs potential to empower them. Importantly 'empowerment' is used as a goal in various human centred design research approaches in healthcare and entails the aim of understanding perspectives of user; patient or clinician so that design development can facilitate emotional, social and cultural needs without fostering a dependence on technology (Hirsch et al, 2000, p.5; Gordon, 2014, p. 60-73; Crabtree et al, 2003, p. 2).

Human centred approaches to general healthcare design include: design ethnography to inspire and inform design creation (Gordon, 2014; Hirsch et al, 2000), mixed methods 
A DESIGN ETHNOGRAPHY OF PELVIC FLOOR EXERCISES

research with ethnographic design to inform further ethnographic research approaches for healthcare (Crabtree et al 2003; Xue, 2009), human computer interaction design and user design research for healthcare (Cafazzo et al, 2012; Park, 2016). Author's voices in these works converge in a resounding need for further human centred fieldwork in healthcare design development (Crabtree, 2003, p1; Hirsch et al, 2000, p 2), and this call for a human centred focus extends into female healthcare design (Xue, 2009; Marques et al, 2010).

Qualitative studies of postnatal women seeking help with PFD symptoms and conducting PFX, some of which are discussed above, have been recorded in medical journals. These texts seek to contribute to a medical body of knowledge and inform practitioners of channels for improvement for patient care based on perspectives of women in interviews or through online surveys (Moossdorff-Steinhauser, 2015; Lagro-Janssen, 2012). While these texts are an invaluable contribution, there is further work required to understand women's and health professional's experiences in a way which will directly help to inform the development of healthcare technologies. Ethnographic design research will be used in this study, this approach enables emotional and social experiences and perceptions to be understood in context and culminates in rich data and holistic outcomes to inform and inspire design (Nova, 2014, p. 34; Dijk, 2010). This method will be described in the methodology chapter. Exploratory methods should remain sensitive to respondents and reflexive to the project it seeks to inform (Crabtree et al, 2003). For this project, the lack of PFX conducted by pregnant and postnatal women has been identified as a social and cultural issue or a wicked problem. Rittel and Webber first coined the phrase "wicked problem" in 1973 (p.158). The term has since been used by Kolko to illustrate that design research can be used to address these problems (Kolko 2012, Chap 3 para 1). Human centred design research can be used to explore perspectives and experiences but also help to address broader cultural issues (Muratovski, 2010, p. 377-378). 
A DESIGN ETHNOGRAPHY OF PELVIC FLOOR EXERCISES

This background chapter has introduced each of these key elements; a social history of female healthcare, PFX and PFX designs and design ethnography research. Each of these components have been shown to be relatively new and are emerging alongside each other emphasising a need for further development. I have underscored that the issue of women not completing regular and correct exercises is a complex and deeply rooted cultural, social and emotional issue. This issue is prevalent and has been and is being addressed through the development of new PFX devices. Literature above stresses the importance of using a human centred research approach to inform the development of future PFX designs, this will be expanded on in the Methodology chapter. 


\section{A DESIGN ETHNOGRAPHY OF PELVIC FLOOR EXERCISES}

\section{Methodology}

This research has addressed the question:

How can women and health professional's experiences with pelvic floor exercise inform the future development of a PFX-assisting system for pregnant and postnatal women?

The issue being tackled is a complex cultural issue which requires an in depth description of the experiences of women and health professionals with teaching and practicing pelvic floor exercises (PFX). Respondent's experiences with PFX have been explored through ethnographic design research. The need for further development of research with a human focused approach in healthcare design has previously been highlighted in the Background chapter (Xue, 2009; Crabtree et al, 2003, p1; Hirsch et al et al, 2000, p 2; Savage, 2000, p1). It's also been emphasised that methods should be shaped for suitability to the context of each individual project (Crabtree et al, 2003, p1; Xue, 2009; Hirsch et al et al, 2000, p 2). Therefore, all of the methods chosen have been informed strongly by similar studies in the literature and shaped to suit the chosen demographic. Methods include; semi structured interviews, informational probes and narrative analysis. Semi structured interviews with health professionals were comprised of open ended questions and lasted about 45-60 minutes to openly explore their knowledge and perspectives. Informational probes (Crabtree et al, 2003, p.4) have been used to explore women's experiences with PFX, they were modelled on the popular \#Challenge posters circulated on social media and sent to women via email. This sought to give a familiar format which was friendly and interactive while also ensuring women's privacy. Narrative analysis was used to collate and organise significant themes in the findings this was done through a colour coding process. Below I have discussed the methods chosen and justification for this approach. 
A DESIGN ETHNOGRAPHY OF PELVIC FLOOR EXERCISES

\subsection{Participants and Recruitment}

The total number of participants recruited is nine, made up of three health professionals and six women who are pregnant or in the postnatal stage. Pregnant and postnatal women are between 22-35 years old with babies up to 12 months old. One woman was 27 weeks pregnant; the rest had young babies ranging from three weeks to three months old. These five women were specifically in the postnatal period (otherwise known as postpartum) which has been described to last up to six months after the birth (Romano, Cacciatore, Giordano, \& La Rosa, 2010).

The health professionals each have experience teaching PFX to pregnant and postnatal women. These health professionals include: a physiotherapist, an osteopath and a woman's health and fitness coach (WHFC), they are all based in New Zealand and have a special interest in pregnant and post natal women's pelvic floor health. For example the WHFC has background as a registered nurse and has run postnatal fitness classes for five years, founding and running a company focusing on safe exercises for pregnancy and postnatal recovery. The osteopath with 19 years in the practice treats mechanical issues of the cranium such as concussion, sinus, tongue problems or ear infection and has a clinical focus in pregnancy, preparation for labour as well as providing osteopathy for babies and children. The physiotherapist also has many areas of expertise but in the past ten years has been focusing on women's and men's pelvic health and has completed post graduate study on pelvic floor rehabilitation.

The osteopath in this study specified that although some osteopaths can work internally they work only externally with the hands. They aid pregnant and postnatal women with pain and give support and therapy through the process of pregnancy and postnatal recovery. All participants recruited were restricted to New Zealand, the majority of the 
A DESIGN ETHNOGRAPHY OF PELVIC FLOOR EXERCISES

recruits abide within Auckland and Wellington. This study was seeking to explore individual's experiences as part of initial exploratory work. This demographic is not representative of all women of this age group in New Zealand.

\section{Recruitment Methods}

This study has full ethics approval, which was obtained through the Victoria University of Wellington's Human Ethics Committee, application number: 0000022545. Informed consent was obtained from all participants and they were given an information sheet and consent form which made clear their role and gave the participants full confidentiality.

Recruitment methods for women included dissemination of posters on social media and to women's groups via email. The idea here was that the group leaders or organisers could pass on the call for women via social media pages. Buggy walks, antenatal classes and new mum's groups were reached via email resulting in a few organisers sharing my posters about this study on their social media pages. Women were also approached in public spaces, this enabled me to describe the project, give information sheets and take down their email address to send them a probe. This successful approach also gave an informal introduction to women's initial thoughts to the project and revealed the general lack of knowledge of PFX as well as forming a relationship with respondents. Twenty women's emails were collected and follow up emails with probes were sent out to them. Of this twenty, there were six returned probes.

Recruiting health professionals was achieved by contacting them via email. Eleven health professionals were contacted with an invitation to participate and information about their potential role in the project. Professionals ranged from; physiotherapists, 
A DESIGN ETHNOGRAPHY OF PELVIC FLOOR EXERCISES

osteotherapists, women's pilates/fitness coaches and midwives in New Zealand. Of these 11, three responded, as described above. I used purposive sampling (Schutt, 2012, p157), seeking to focus in on these two specific groups of pregnant and postnatal women and health professionals. The snowballing method was also employed as recruiting people for such a sensitive topic of study could be daunting for potential recruits when approached without initial contact or knowledge of the researcher. By introducing myself in person connections were formed, this personal approach was continued through participants sharing the call to study with friends and family (Schutt, 2012, p158). Two of the six postnatal women participating in this study were reached through the snowballing method.

\subsection{Exploratory Methods}

Exploratory methods included semi structured interviews for health professionals and probes for women respondents. As methods in this area have been described to be highly underdeveloped (Xue, 2009; Crabtree et al, 2003, p1; Hirsch et al et al, 2000, p 2; Savage, 2000, p1) similar studies which used ethnographic design research for the development of healthcare design were used to draw lessons from which helped to shape exploratory methods for this project. The probes were also shaped by the apparent needs and lifestyle of the demographic.

There was a significant need to draw attention to the role of medical staff if they are connected to the future use of technological health devices (Hirsch et al, 2000, p5; Furniss et al ,2014 p62, Gordon, 2014, p 22-23;Xue, 2009, p 34). The need to work with health professionals in some capacity was echoed by stakeholders within the umbrella project. Forty-five to sixty minute long semi structured interviews were prepared, and the questions chosen were informed strongly by previously discussed similar studies. For example 
A DESIGN ETHNOGRAPHY OF PELVIC FLOOR EXERCISES

questions related to similar technologies were included as this focus is described as important for the development of health technologies (Caffazzo et al et al 2012, p10; Furniss et al 2014, p1; Xue,2009, p3; Hirsch et al et al 2000, p 1-4; Crabtree et al 2003, p1). In line with similar studies suggestions, the semi structured interviews also explored how correct PFX is taught and potential thoughts about barriers and motivations that affect pregnant and postnatal women with regular and correct PFX. Some studies (Hirsch et al, 2000, Gordon, 2014) strongly relied on openly exploring all aspects of one phenomenon to identify how and if design could play a role, this enabled the process to explore all potential (Hirsch et al, 2000, p 2; Gordon ,2014). Therefore questions written for the semi structured interviews were written to encourage an open discussion and allow for respondents to reflect and explore their own experiences, this was achieved for example by starting questions with phrases such as "tell me" or "describe/explain." Consequently, the suggestions of a need for open ended explorations also informed the decision to use an informational probe (Gaver, Dunne \& Pacenti, 1999) as a method of investigation, which is detailed below.

\subsection{Probe Details}

A probe enables the women to not only answer but explore and reflect on their own experiences, allowing unexpected new knowledge to arise through a variety of engaging activities making up the probe (Gordon, 2014;Crabtree et al, 2003, p.3; Hirsch et al 2000, p2). Crabtree et al adapted Gaver's cultural probe, focusing more on collecting information and understanding the lives of respondent's than collecting materials for inspiration (Crabtree et al, 2003, p.3-4). This adaptation of a cultural probe could also be called an 'informational probe', for clarity I refer to the probes as 'informational' throughout this paper, as this study has adopted this approach to cultural probes. It's reinforced that in obdurate settings an 
A DESIGN ETHNOGRAPHY OF PELVIC FLOOR EXERCISES

informational probe offers exploration and insight into lives and experiences and it's aim is to inform design, however inspiration for design is acknowledged as a by-product of this (Crabtree et al, 2003, p. 4).

As exploring user needs in a "sensitive setting" are largely underdeveloped, there was little guidance in terms of probe designs which would be suitable (Crabtree et al, 2003, p.1). Instead I developed a probe which was informed by the demographic, it was crucial that it was designed with a strong awareness of women's condition and lifestyle (Gordon, 2014; Crabtree et al, 2003, p.3). Friends and acquaintances who have had children recently helped to give insight, namely highlighting the busy time schedule of new mothers, they also gave attention to this age group's familiarity with social media. Based on feedback from supervisors, experience designers, and acquaintances with infants as well as having talked to potential respondents as I handed out posters for the research, it was clear that phones were often in use, and mums were (in general) aware of and using social media and email. With this in mind as well as the busy lives of mums and pregnant women I constructed a poster based on the \#Challenge posters that are circulated on social media, it was made up of questions and activities that could be sent to women in an email. I edited the content several times based on feedback from women in this age group (both with and without children), my supervisors and an experience designer. By sending it out to a variety of people I could test it to ensure it was easy, simple to follow and relatable for women who have new babies or are pregnant.

\#Challenge posters are often used in online spaces such as; Facebook, Instagram or Twitter, they are a single shareable image often with prompts or numbered activities. Individuals who take part in the \#Challenge can share their experience by tagging any posts or photos with a '\#' and the name of the challenge. Some individuals and groups use this 
A DESIGN ETHNOGRAPHY OF PELVIC FLOOR EXERCISES

format to spark social change and raise awareness about an issue or phenomenon among their friends and followers on social media.

The design and visual presentation of these posters is of little consequence as it varies dramatically as with any poster, the defining features of these posters are their content which includes written prompts that encourage individuals to participate in individual activities and share their experiences on social media. This content is often communicated in an informal tone and aims to raise awareness about an issue or organisation. For example Mental Health Foundation of New Zealand (MHFNZ 2016) has used this style of poster to help to promote awareness about the organisation and to encourage individuals to look after their own mental health. For example MHFNZ's '\#photochallenge' gave a list of themes that encouraged people to do something meaningful and take a photo of it. This particular challenge gave a theme a day for 12 days leading up to Christmas day, this included : "1. Tidy Kiwi, 2. Random Act of Kindness, 3.Garden, 4. With a Bro" (MHFNZ 2016). It encouraged people to post their photos and tag them with "\#MHFNZ" and "\#HealthyNatureHealthyPeople" on Instagram, Twitter or Facebook (MHFNZ 2016). These titles act as prompts to conduct an activity and take a photo of that moment and share it on social media.

The requirements of ethics approval for my project (confidentiality for participants) and the need for a private and sensitive probe meant that utilising social media was not an option in this study. Perhaps a more public discussion would be something to look to in a future project - and may potentially add to a sense of empowerment through building a community and raising awareness. However, in this project for the sake of the ethical considerations and offering a feeling of privacy and security the probe was arranged only based on the familiar key features of shareable digital posters. A private email with the name ' $m y P F X$ ' in the address was provided for women to send their completed response to. It was 
A DESIGN ETHNOGRAPHY OF PELVIC FLOOR EXERCISES

explained to the women that there were a group of women which would be taking part in this, perhaps offering a sense of community even if they could not interact directly. Through the use of a \#Challenge poster individuals may also be given the sense that their contributions are each a valued part of addressing a larger issue (which they are).

Informational probes have been described in other works to encourage individuals to take photos, create or imagine other ways of living and reflect on experiences in diaries, poetry or metaphor (Gaver, Dunne \& Pacenti, 1999). I have noted that similarly the popular \#Challenge posters disseminated online do the same as probes in this respect. So perhaps this approach familiarises the concept of a probe for the women. 


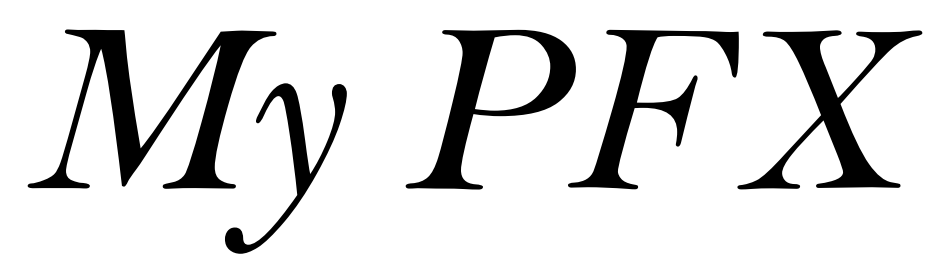

\section{My PF eXperience}

Imagine your closest female friend wants to know what it's like to do pelvic floor exercises (PFX), use a metaphor* to explain to her what it's like;

*Metaphor means to explain what something is like for you by comparing it to anything else which you feel represents the experience best. There are no wrong answers.

1a) Have you ever been taught how to do pelvic floor exercises with metaphors before? Explain who taught you and what was said;

1b) Describe anything else that has been used to teach how to do these exercises;

\section{My Letter}

Using the prompts below write a short letter to your pelvic floor exercises as if they are a partner (it can be a love letter, break up letter or something in between. Write as much or little as you like).

Dear PFX,

Our relationship has been...because...

When we first met I felt... because.... At the moment I see you...times a week which makes me feel... and ...because...We are at our best together when... We are at our worst when... In the future I hope...

What I really want you to know is....

Love from...

\section{My 'SNAPS'}

Take a photo* of the three most common spaces you do PFX and fill in the sentences below for each snap; I do my PFX here because... When I do them here I feel...

This shows the questions featured on the probe poster sent out to women. The poster was a colourful single PDF document, to be shared, downloaded, viewed and responded to via email which included instructions and friendly notes. 
A DESIGN ETHNOGRAPHY OF PELVIC FLOOR EXERCISES

The activities prompted on the poster were broken into four parts; first a metaphor based question, then a letter activity with prompts. Thirdly, a photo-taking activity which asked for photos of spaces PFX is regularly and most commonly done in with written reflective captions. And finally, a description of any devices or apps that are used currently for general health or PFX. I will illustrate below the reasoning behind choosing each of these probe prompts.

\section{Metaphor Activity}

The first activity on the digital poster was a metaphor based activity, designed to understand how women experience the exercises physically, mentally and how they discuss it with friends. The use of the term metaphor is commonly a literary comparison of one subject to another, it is described by Burke "[Metaphor is] a device for seeing something in terms of something else. It brings out the thisness of that or the thatness of a this" (1945 cited in Saffer, 2005, p.1). Conceptual metaphor is shown to be a useful way to abstractly work through/interpret or express "an embodied phenomenon" for design (Blackwell, 2006, p.493). A conceptual metaphor is also abstract and gives space for discovery and insight helping to improve learning and understanding (Blackwell, 2006, p.498). This can be useful in creativity studies research, for example Gauntlett a Creative Studies Lecturer, uses a platform of Lego or pipe cleaners and other playful craft materials to enable people to manifest their metaphors and talk about it giving space for new ideas or realisations (Gauntlett, 2015).

Aside from its use in research and design, metaphor is tightly woven into our daily lives in everyday language (Saffer, 2005, p.6). In the example of pelvic floor disorder (PFD) it's been shown already that metaphors are used by health professionals to teach PFX for example the Pelvic Floor First website, used and promoted by health professionals describes 
A DESIGN ETHNOGRAPHY OF PELVIC FLOOR EXERCISES

how women can exercise their pelvic floor, the second step is titled "visualisations" giving examples of ways one can learn PFX (2016).

Additionally, a qualitative study of 40 New Zealand women postulates that metaphors are often used alongside anatomical knowledge, communicating physical experiences and any social or cultural understandings connected to pelvic pain (Grace \& MacBride-Stewart, 2008). All together this supported the formulation of a three part question prompting women to describe any metaphors they have come across to teach PFX. This included: how they would teach a friend to do the exercises with a metaphor and finally for the sake of remaining explorative and open to,"describe any other ways pelvic exercises have been taught." The metaphor focus has been used in order to explore aspects of the physical and visual experience of women in learning and practicing the exercises. A focus on metaphor is used to understand how exercises are verbally and visually communicated. Through such a focus, it was intended that insights could give verbal and visual prompts to inform and inspire the development of future PFX designs. This approach has also been used to give women an open ended prompt to personally reflect on the physical and mental experience of practicing PFX.

\section{Love Letter Activity}

The second question gave prompts for a love letter written to the women's PFX (Hannington \& Martin, 2012, p. 114). Love letters or break up letters are still developing and more literature on a variety of approaches for love letters is called for by Gerber who uses break up letters written to technology as a way of understanding the relationship between user and device as well as giving an open space for emotion through the act of writing (Gerber, 2011 p.137-140). I have designed this activity with pelvic exercises taking up the role of the 
A DESIGN ETHNOGRAPHY OF PELVIC FLOOR EXERCISES

partner to write to, with an option to write a 'love letter' or a 'break up letter' if desired. This gave women a way to work through their private experiences with a fictitious scenario in which the pelvic floor exercise itself is a partner. In iterating and editing these questions with feedback from experience designers, mentors and friends of this age demographic it became clear that the instruction to write was too open and some direction was needed for women so that the empty page was not seen as a barrier to writing. Short 'sentence starters' were included for this activity with a final prompt; "what I really want you to know is...", offering space for any prevalent feelings or thoughts to be expressed without being limited.

\section{Photo Activity}

Finally the "My Snaps" section sought to explore women's everyday regular environment and where the most common spaces for doing exercises are. Asking women to communicate what this space looks like, describe how it feels to do exercises there and explain why they do them in that space, this aimed to add an emotional mapping dimension to the question, showing emotions felt in various places while doing exercises (Wherton et al 2012, p7; Roscam,2010, p102). Hirsch et al used probes with a documentation log book and camera to show important services, interactions and documentation of significant spaces for the individual. The aim of this was to show what is improvable, felt and experienced and to reveal opportunities for design (Hirsch et al 2000, p2). 
A DESIGN ETHNOGRAPHY OF PELVIC FLOOR EXERCISES

\section{Technology Question}

The final fourth question explored women's experiences with similar technologies which has been discussed previously as this question was informed by previous similar studies (Caffazzo et al 2012, p10; Furniss et al 2014, p1; Xue, 2009, p3;Hirsch et al, 2000, p. 1-4; Crabtree et al, 2003, p1). The questions chosen for the probe and semi structured interviews were shaped by the need to inform the future development of 'R-Leaf' (described in the Introduction chapter) and the future development of similar designs and systems. The demographic was also a point of focus ensuring the style of the probe was suited to the lifestyle of the respondents. Similar studies were used to decide on the best methods to use and to direct the focus of the questions.

\subsection{Narrative Analysis}

Ethnographic design research has been described to be best used to explore emotional and social experiences in context and enable rich data and holistic outcomes to inform and inspire design (Nova, 2014, p. 34; Dijk, 2010). As design ethnography seeks to understand the perspectives and experiences of individuals, the challenge was how to analyse and present these holistic findings in a clear way without losing the richness of the information gathered, this lead to the decision to use narrative analysis which will be detailed below.

Design ethnography used in a commercial setting often does not align with academic methods of analysis as the "AEIOU" approach is used; grouping data into "Activities Environments, Interactions, Objects" and "Users" (Nova, 2014, p. 53 -55). Visually coding and sorting information into groups with other filters was also described to be used as well as organising the data into 'themes' to present findings (Nova ,2014, p.53-55). This was exemplified further in similar study papers such as Hirsch et al's, The ELDer Project: Social, 
A DESIGN ETHNOGRAPHY OF PELVIC FLOOR EXERCISES

Emotional, and Environmental Factors in the Design of Eldercare Technologies (2000). The approach taken in this research was to represent the found data through themes and discuss similarities and differences, as this was in line with the presentation of other human centred design research outputs that seek to inform design.

A method of analysis which aligns itself with this need to analyse thick data while also ensuring the detail and depth of the finding is not lost, is narrative analysis. Education researchers Connolly and Clandinin have underlined the flexibility of narrative analysis within many social science fields, describing it as a way to explore and manifest human experiences and phenomena (Connelly and Clandinin, 1990). Narrative analysis was seen as fitting for a project focused on healthcare and potential patients perspectives, as it has commonly been used in nursing and medical journals, such as Stevens (1993) who uses narrative to explore the experiences and perceptions of patients. More recently, Gazan (2005) underscored the use of a narrative approach in design research for the design of a system in a library, although not related to healthcare this exemplifies a design research project which employed narrative analysis to give weight to the in depth and explorative nature of design ethnography research and findings. This study emphasised the need to communicate findings without claiming it as fact, giving space for new ideas and questions to arise (Gazan, 2005, p.348).

Riessman explicated the relevance of narrative analysis for sensitive settings and for the study of macro phenomena such as social, political or cultural change (Riessman, 2001). It was highlighted that some phenomena can be missed out by respondents, but that other perspectives and background research can be included in the findings to reveal overlooked gaps or themes and offer further context to the themes found (Gazan, 2005). By compiling themes and perspectives of women alongside health professionals and giving further context 
A DESIGN ETHNOGRAPHY OF PELVIC FLOOR EXERCISES

through relevant literature the narrative analysis enabled a discussion of findings which was subjectively shaped by perspectives, context and the focus of the overall project.

In conclusion to this chapter, exploratory methods used for this research have been chosen based on suitability to the project and are informed by similar studies. Narrative analysis is adopted to enable themes and differences to be included in the final discussion, offering holistic findings. These findings will be presented in the following chapter and how these findings can inform the future development of PFX designs will be clarified further through the corresponding design recommendations. 
A DESIGN ETHNOGRAPHY OF PELVIC FLOOR EXERCISES

Findings and Design Recommendations

As discussed in the methodology chapter, methods have been used to openly explore experiences with practicing and teaching pelvic floor exercises (PFX) and these findings have been analysed resulting in themes. This chapter presents the holistic findings of this work through theme headings, direct quotes and a design recommendations list as well as referencing background literature. The first theme; Safety and Professional Support describes a need shown by health professionals for professional screening and diagnosis. This theme also highlights that women need professional support in the form of guidance of how to practice PFX correctly. The second theme; Teaching PFX with Metaphor underscores how knowledge of the pelvic floor and body facilitated with props such as a model of a pelvis can aid women's knowledge of PFX. It is discussed that metaphors which are connected to women's understanding of their bodies can facilitate correct practice of PFX. Thirdly, Integrating PFX into Daily Life shows the need for 'functional pelvic floor exercise' to be practiced as part of daily life alongside lifestyle modifications, and exercises which are suited to women's busy lives. And the final fourth theme; Device Concerns and Feedback discusses concerns health professionals have around an insertable device as well as discussing a selection of device feedback comments.

\subsection{Safety and Professional Support}

The health professionals who participated in this study emphasised the importance of screening and professional diagnosis to ensure the women's safety. Mirroring this, women expressed a want for guidance to ensure exercises are correct and safe, as well as motivation and reminders to do the exercises. 


\section{A DESIGN ETHNOGRAPHY OF PELVIC FLOOR EXERCISES}

\section{Screening and Diagnosis}

Each of the health professionals have a way to ensure women can conduct the professionally recommended exercises correctly and safely. The physiotherapist can use digital examination which enables the cues given to women to be trialled and tested, they can watch to see if the main "lift and squeeze" cue works and if not try other metaphors to see which works best. The osteopath explained that they work manually and externally (although some can work internally if possible to guide women through exercises). Whereas the Women's Health and Fitness Coach (WHFC) explained that they have collaborated with a gym and use ultrasound to see if women are conducting the exercises correctly. The women's WHFC explained that they recommend women who have pelvic floor issues to see a physiotherapist, if women do not pass rigorous screening the WHFC cannot diagnose women, but can help with exercises once a diagnosis is made. Similarly, this screening was also discussed to be conducted by the physiotherapist before examination, followed by professional diagnosis if required. This illuminates the need for a rigorous screening process before further examinations and a diagnosis can be made. For example the Pelvic Floor Screening Tool Downloadable PDF from the Pelvic Floor First website was discussed to be used by the fitness professional and physiotherapist (Continence Foundation Australia, 2014). This reinforces that if there is a health concern or issue, professional diagnosis is important to offer women correct guidance. As described by the physiotherapist and health trainer some women may have a need to practice relaxing the muscles, which means the wrong exercises could worsen a woman's condition and cause pain, so screening, professional diagnosis and guidance is needed. 


\section{A DESIGN ETHNOGRAPHY OF PELVIC FLOOR EXERCISES}

\section{Guidance and Motivation}

Women believed that guidance in exercises was crucial as PFX was perceived as an elusive and complex practice to conduct as required. Issues women raised included a need for more education around exercises as well as a need for motivation and reminders. For example, women (even women happy with their progress through exercises) expressed a desire to practice much more in the future and underscored that their relationship with their PFX is at its worst when they forget, are too busy to practice or when symptoms remain or worsen due to lack of practice. Additionally, five women described their relationship with PFX as "rocky", "unknown" and "on and off", each expanded on this by drawing on the fact that practicing PFX is an up and down journey due to uncertainty of how to practice, forgetfulness and lack of knowledge of PFX. Supplementary to this, two of the women highlighted that there was a gap in their lives in which they didn't know about PFX. For example, "our relationship has been long distance because no one has spoken to me about you since my first child was born 3 years ago." This participant hasn't had anyone speak to her about PFX since her first child was born three years ago and the other does PFX now but previously had not had such an intimate relationship with her PFX. Some women also emphasised that they had to teach themselves about PFX in order to do it by reading books, magazines or looking online.

They each answered the sentence "what I really want you to know" as if it was written to their exercises, and three of the women emphasised that they wanted more knowledge and motivation. For example:

"What I really want you to know is I have forgotten everything I was told 3 years ago other than to squeeze and hold for a bit Love from, Me"

"What I really want you to know; is there anything new we can do to set the spark 
A DESIGN ETHNOGRAPHY OF PELVIC FLOOR EXERCISES

alight again?"

The theme of lack of knowledge and motivation was continued as women highlighted their experience with their first PFX. For example the majority of women explained that when they first tried to do PFX it felt "weird" or "strange" making them feel "silly" or "uncomfortable." To expand on this, some of the women highlighted that they felt this way the first time because no one had told them about it before and it was a strange sensation:

"When we first met I felt discouraged because it was just another thing I should be doing but didn't want to and just felt a little weird, almost ticklish."

"When we first met I felt weird and uncomfortable because no one has ever talked about you before."

"When we first met I felt silly trying to control my muscles."

"When we first met I felt strange, because I hadn't felt you move before."

These responses highlight that exercises can not only be forgotten and hard to fit into daily life but that they initially made women feel "uncomfortable," "strange" and "weird." Women in this study highlighted the need for support in terms of being taught how to do the exercises, they wanted motivation, and guidance to ensure that the exercises were being done correctly.

The findings from responses to the cultural probes demonstrates that all of the six participants recognise that guidance including reminders, motivation and education would aid in a more stable relationship with their PFX. Complementary to this theme among women, the health professionals echoed a need for screening and professional diagnosis as well as guidance to ensure exercise are carried out correctly according to individual woman's specific health needs. 


\section{A DESIGN ETHNOGRAPHY OF PELVIC FLOOR EXERCISES}

\subsection{Teaching PFX with Metaphor}

The way that metaphors are used to describe the act of practicing PFX was a focus of the probe with pregnant and postnatal women. Metaphors for teaching PFX were also a discussion point in semi structured interviews with health professionals. A focus on metaphor in this fieldwork saught to explore how exercises can be verbally and visually communicated. Through such a focus, it was planned that insights could give verbal and visual prompts to inform and inspire the development of future PFX designs. This approach has also been used to give women an open ended prompt to reflect on the physical practice of PFX.

\section{Visualising the Pelvic Floor}

The health professionals emphasised that the visual cues which they most commonly used for women revolved around showing patients a model of the pelvis and giving information about the pelvic floor before any exercises or further examination was done. For example the osteopath took a small anatomical model of the pelvis cupped in one hand:

"What I usually do is I show them the pelvis and I tell them it's like a sling, like this [makes a 'sling' with hands cupped under the model where the pelvic floor would be]. I'll get them to imagine a point in the centre of that sling and feel that they are drawing that up and I usually get them to do that on the out breath, so they breathe in to prepare and breath out and draw it up on the out breath."

This illustrates how the woman is shown the pelvic model and encouraged to visualise a point in the centre of her own "sling", or "pelvic floor", and to imagine it lifting up as they breathe out. The WHFC also used a descriptive technique to teach women to visualise their pelvic exercises. For example:

"I have used loads overtime. But I just tend to use one now. Which is just drawing the tail bone towards the pelvic bone. So asking women to think about where their pubic bone is, [and] thinking about drawing those together and just lifting the muscle that's in between those two points, just lifting up the entire pelvic floor. So it's just draw coccyx to pubis and lift ,lift, lift!"

This descriptive technique worked to enable women to visualise their whole pelvic 
A DESIGN ETHNOGRAPHY OF PELVIC FLOOR EXERCISES

floor and concentrate on lifting the whole of it up. Similarly, the physiotherapist also used a pelvic model to educate first and explained that when conducting the internal exam instructions are given to:

“[S]queeze and pull up inside' so I talk about 'squeeze and lift'. Because you don't want just squeeze or just lift. So there should be a squeezing and a movement."

The physiotherapist highlighted that most of the time they are conducting an internal exam, so the information given to the woman with the aid of a model pelvis can help to prepare and inform the women of what the exam involves. The physiotherapist highlighted that they would first have the woman's history and from that point would inform the patient about what the exam is for and what it will involve. The physiotherapist explained that they don't teach the women how to do the exercises until the exam is in progress. It was said that the effectiveness of the cues given can be seen by watching the sphincter and cervix movement or through the finger on the vaginal wall to feel if the muscles are engaged correctly.

Each of the health professionals talked about an upward movement; whether it's "squeeze and lift" or "pull up" and used education about the pelvic floor with the aid of a model pelvis. This enabled them to teach what needs to happen so that women can learn and visualise their exercises by thinking of the pelvis and lifting their pelvic floor inside this structure. Education has also been underscored in previous literature, and is described as an important part of enabling and empowering women to understand their bodies. For example, a project called Pelvics emphasised a need for women to gain further knowledge about their bodies (Almeida \& Arrigoni,2014-16, p. 1-2). Additionally, even with knowledge of needing to do exercises it's been highlighted that women may not know how to do them properly (Chiarelli, Murphy \& Cockburn 2003). This reinforces a need for further education and awareness of the pelvic floor and the benefits of correct and regular pelvic floor exercise. 


\section{A DESIGN ETHNOGRAPHY OF PELVIC FLOOR EXERCISES}

\section{The Body in the Metaphor}

When women discussed the way that they would describe to a close female friend what it's like to do PFX and to use a metaphor to explain this, they each chose a metaphor that was literally connected to the body. It was also highlighted by health professionals that the majority of women find education about their pelvic floor anatomy useful for PFX, however, it was added that if women continue to struggle with locating and activating their pelvic floor then further metaphors can be tested out with supervision to see if the exercise is being conducted correctly. These metaphors most commonly related to physical everyday movements or sensations of the interior body. For example, the physiotherapist explained:

"So I'll talk about squeezing around a tampon, and pulling up inside or trying to stop your flow of urine, always if I use that one I always say 'don't use that on a regular basis'. [T]rying to 'stop passing wind' sometimes but usually the squeeze and lift. Trying to do it as if your squeezing up around a tampon usually works."

The WHFC explained that the "coccyx to pubis" metaphor gives points of reference and helps women to lift the whole pelvic floor. They explained that the other familiar cues such as "vaginal lift" and "squeeze a tampon" or "squeeze and stop the passage of wind," "stopping the passage of urine" helps some people but they highlight that this focus on specific parts perhaps may not enable women to lift and exercise the whole muscle.

The osteopath underscored that they sometimes use metaphors specific to the vaginal or anal areas depending on what the women need to practice such as "stopping the flow of urine in the front " or "draw up more in the vaginal area, or they can draw up in the anal area." In contrast to these views the physiotherapist highlighted that when they get women to focus on the different areas, it has the same effect on both areas, so although focus might be on one area both the anal and vaginal muscles come into action together:

"[Y]ou can focus on the back, and squeeze at the back, but if I'm getting my women to do that in a vaginal exam; squeeze around the back and then squeeze around the 
A DESIGN ETHNOGRAPHY OF PELVIC FLOOR EXERCISES

front then you get the same thing happening. You can focus on the back and feel it more at the back but actually when you measure it you are getting the same than if you focus on the front. Sometimes you look on websites where they are saying squeeze at the front, squeeze at the middle, squeeze at the back but actually you are doing the same thing."

These perspectives differ slightly depending on the professional, however they each illustrate ways health professionals use metaphors related to the body to aid women with exercise. When women discussed the way that they would describe to a close female friend what it's like to do PFX and to use a metaphor to explain this they each chose a metaphor that was literally connected to the body. The question was open, so in theory abstract metaphors could also have been used to describe the experience. However describing how to practice PFX in terms of other physical actions was a common theme among women. There was one deviation from this focus on the body which can been seen in an answer below, this was "imagine a plunger" and was followed by a body focused metaphor, despite this the main theme among women was to describe PFX in relation to the body. For example, women explained:

“Tensing your pelvic floor muscles feels like you're gathering your muscles together to stop yourself from letting out a flatulent."

"So, metaphors I'd use would be imagine a plunger, or compare it to your diaphragm when doing deep breathing exercises."

"It's like tightening the lid on a bottle."

"Squeeze like you are stopping yourself from going to the toilet."

"It's like pulling a tampon up inside your vagina without using any hands."

One woman explained that she had previously not had to focus on her pelvic floor muscles, however through online research and reading other material she began to learn more. She explained that PFX are recommended by doctors and midwives, but also explained that in order to do this properly you need to know how to engage the right muscles: 
A DESIGN ETHNOGRAPHY OF PELVIC FLOOR EXERCISES

"To do so, sit or lie down with the muscles of your thighs, buttocks and stomach relaxed. Squeeze the ring of muscle around the back passage as if you are trying to stop passing wind. Now relax this muscle. Squeeze and let go a couple of times until you are sure you have found the right muscles. Try not to squeeze your buttocks. When sitting on the toilet to empty your bladder, try to stop the stream of urine, then start it again. Do this to learn which muscles are the right ones to use - but only once a week. Your bladder may not empty the way it should if you stop and start your stream more often than that."

This final example shows an understanding of the importance of engaging the right muscles. Notably, although other women had varying degrees of knowledge and different experiences of PFX they each chose metaphors which connected to physical functions of the body such as trying to stop passing wind to describe what PFX is like. A qualitative study by Grace and MacBride- Stewart (2008) signalled that metaphors are a common and useful way for women to understand and communicate pelvic pain. This study was of 40 New Zealand women who suffered from pelvic pain. While it was focused on pelvic pain this study similarly found that where an image of the body's interior can't be seen or easily imagined there is often a desire for the image (Grace \& MacBride-Stewart, 2008, p.118).

For example:

Women narrate the physicality of their bodies; the pelvis in pain in anatomical terms, as bodies with functional or dysfunctional organs, a finding also reported by Savidge,

Slade, Stewart and and Li (Grace \& MacBride-Stewart, 2008 , p.185).

MacBride-Stewart and Grace's qualitative study of pelvic pain highlighted the complexity of the pelvis (which holds the pelvic floor), describing that the fact it is unseen

fuels a desire to identify, locate and understand it and the pain within it (2008). This discussion connects to the theme of The Body in the Metaphor, as it's been found overall that the visualisation chosen to illustrate the practice of PFX is connected to images of movement within the body or familiar physical actions of the body. 


\section{A DESIGN ETHNOGRAPHY OF PELVIC FLOOR EXERCISES}

An additional metaphor that puts focus on visualising your pelvic floor is a silk scarf metaphor designed to help women to relax the pelvic floor. The physiotherapist also highlighted that there are different visualisations for women that need to relax the pelvic floor. However there are different exercises that are done to relax the pelvic floor. The physiotherapist gave an example of a metaphor used to help women to relax their pelvic floor:

"Imagine that you're sitting on a silk scarf and pulling up, into the vagina and then dropping it down, you have to imagine you have a scarf like that (gestures like a scarf is lightly laying on the seat) and then it just sort of wafts up."

It was explained that by imagining drawing the scarf up you have an awareness of your muscles but then you focus on dropping the scarf down to relax the pelvic floor. It was also emphasised that the act of practicing PFX for the first time is something which feels "strange and unfamiliar" so in itself it is abstract and hard to articulate which could point towards a need for a deeper or existing knowledge of the body to facilitate learning PFX. Individual's further education about the body has been highlighted as vital in seeking to aid women's understanding of pelvic pain (Grace \& MacBride-Stewart, 2008, p.1). It is demonstrated with the subthemes above that health professionals see value in educating women with visual models of the pelvis in order to teach PFX. Also illustrated above these women demonstrate a need to understand and communicate PFX in terms of other familiar movements of the body.

\section{Visualising the Holistic Body}

The WHFC used two props as part of educating women; a rubber chicken and a biotensegrity model. The rubber chicken had a thin film of rubber which ballooned from its rear once pressure was applied to the stomach. This rubber chicken was explained to be used to demonstrate the negative effects of intra-abdominal pressure which may occur when 
A DESIGN ETHNOGRAPHY OF PELVIC FLOOR EXERCISES

coughing or carrying out physical activities. This pressure build up can cause symptoms of PFD such as prolapsed (POP). The chicken was a physical metaphor with the aim of educating visually. Additionally a biotensegrity model was used, this model is said to give a representation of how the pelvic floor moves with the body and how movement and physical activities impact your pelvic floor. After follow up questions sent to the WHFC enquiring further about the model they explained:

"It is used to demonstrate how your pelvic floor is connected to other muscles and how the pelvic floor reacts with movement. It shows relationships with other muscles and lets people know how a tightness or a weakness in our musculoskeletal system impacts on the rest of the body. The design is modelled on some of the work from Buckminster Fuller a well known architect. This model was used as a teaching tool when I was training in advanced postnatal exercise in the UK. I was so intrigued I bought one."

Tensegrity is defined as: "a design principle that applies when a discontinuous set of compression elements is opposed and balanced by a continuous tensile force, thereby creating an internal pre-stress that stabilizes the entire structure" (Scholarpedia, 2012). The tensegrity theory has been given growing attention by biologists and physicians as well as massage therapists over the last 20 years as body tissue and organs have been shown to play a crucial role in overall body function and health (Ingber 2003; Levin, 2002). The use of a tensegrity model shows one way in which health professionals may teach women about the importance of a holistic awareness of your pelvic floor. The osteopath also discussed this holistic approach to the body, emphasising the complexity and interconnectedness of each of its parts. The physiotherapist also emphasised the importance of remembering that we have a "body" not just a "pelvic floor."

Although each of the professionals have varying approaches to PFX I have labelled this key theme as Visualising the Holistic Body to underscore that health professionals each aim to teach women not only about their pelvic floor but everything of relevance to that patient including everything that is impacted by or can impact it, and to give examples of 
A DESIGN ETHNOGRAPHY OF PELVIC FLOOR EXERCISES

how this may be taught visually. Additional to this, Pilates which will be discussed below may offer a way for an understanding of the 'holistic body' to be communicated in relatable terms. This theme highlights the need to give women an awareness of their pelvic floor; this may be achieved further through 'functional exercises' as well as lifestyle modifications which will be discussed below.

\subsection{Integrating PFX into Daily Life}

The need to make women aware of the impact that lifestyle and physical daily activities has on the pelvic floor was made clear through discussion with health professionals. This theme also highlights that women understood PFX as an exercise which is done amidst daily activities. From the perspectives of health professionals and women the integration of PFX into daily life has great potential for design if it is caters to both their timetables and health needs.

\section{Functional Exercise in Daily Life}

Overall, health professionals teach women that the pelvic floor can be affected by other health conditions and lifestyle. Health professionals underscored a need for women to understand the everyday lifestyle factors that can worsen PFD or put pressure on the pelvic floor. Factors such as childbirth, obesity, trying to get fit after pregnancy (lifting weights, crunches, jumping etc), lifting the baby, straining during bowel movements, back issues, and menopause were all described to impact the pelvic floor as it is part of your core body, and can therefore adversely impact your health. These findings are reflected in the literature as Parkin (2012) illuminates, "current treatments for postpartum pelvic floor dysfunction include lifestyle modifications, pharmacological therapy, and physical therapy" (p.3). This demonstrates that lifestyle modifications are seen as a treatment for PFD and should be 


\section{A DESIGN ETHNOGRAPHY OF PELVIC FLOOR EXERCISES}

encouraged. Once an awareness of how your lifestyle and physical activities effects the pelvic floor is established the benefits of 'functional exercise' becomes clearer.

It was explained by health professionals that women need to know the pelvic floor is part of the core so the practice should include "functional exercises." Functional exercise is a term used by health professionals in the interviews to describe PFX which are done alongside everyday activities or movements. For example the pelvic floor can be tightened and relaxed during lifting a baby, laughing, running or sneezing. This was echoed by Marques, Stothers and Macnab, their work illustrated that one of the key factors of muscle training is the principle of 'specificity', this means that the PFM should be "trained with physical activity that replicates as closely as possible the functional movement required" (Marques, Stothers \& Macnab, 2010, p. 421). To illustrate this further I have used an example from the WHFC:

"I think we need to move on from just doing pelvic floor isolation stuff, because as I said before the pelvic floor works with the other four core muscles, normally, functionally, that's how the whole core works, so if you can just do that in your normal day. [S]o exhale and lift your entire pelvic floor as you're doing an activity; [p]icking washing up off the floor, hanging up something - lifting up [sic] , anything when you exert, lift your pelvic floor up; then, then you're actually doing your pelvic floor exercise."

Similar to this, the physiotherapist explained that practicing Pilates or women's health

fitness can be a good way for women to continue to build strength and recover in a "functional way". The physiotherapist also highlighted:

"[T]he pelvic floor is involved with Pilates and the core, so some of the exercises I might give women (the functional exercises), you could call it Pilates or you could call it physiotherapy, but it is both really I suppose."

Pilates is defined in the Cambridge dictionary as "a brand name for a system of physical exercise involving controlled movements, stretching, and breathing"(Cambridge University Press, 2017). Functional exercises given in physiotherapy sessions are described here as much the same as Pilates, due to the connection between mind and movements of the 


\section{A DESIGN ETHNOGRAPHY OF PELVIC FLOOR EXERCISES}

body as a form of exercising. Comparatively the relevance of incorporating exercises and pelvic floor muscle awareness into the everyday was highlighted by the pregnant and postnatal respondents on some level. Although functional exercises were not mentioned there was an awareness of the need to practice PFX regularly and it was discussed that PFX is easiest to practice alongside daily activities. This need has been highlighted by the osteopath who explained that everyday activities can become reminders to doing PFX:

"Women invariably forget. So we tie it in with; brushing your teeth or breastfeeding your baby, just in the first couple of minutes or something, just maybe try and get ten done, three times a day; kettles boiling- go for it! Stopped at a traffic light? Do it. Waiting to cross the road? Do some more. You know different things work for different people and another one is when you are two or three minutes from home and you turn that corner, and do pelvic floors for that last bit. They do need it tied into something to make them get it done."

Women highlighted a range of people and approaches from which they had first learnt about PFX and how to do it, from physiotherapist's guidance to online independent research. Women recalled learning about the pelvic floor and practicing how to identify the muscle on the toilet, during sex or being instructed to do the exercises while feeding the baby. This emphasised a need to relate exercises to, and incorporate them into daily life. For example:

"I was taught by a physiotherapist that they organise for you after you have had a baby in the UK. Just counting and holding."

"Do while feeding as you will be sitting down unable to go anywhere so good multi tasking [sic]."

"Okay so from what I remember no one really taught me how to do them [...] I think it was something I came across online one day when I was rather bored. I'd read somewhere about a girl who could make herself orgasm though doing pelvic floor exercises, cool huh? Anyway I knew I didn't want to pee myself when I got a bit older so started practicing around age 18ish and discovered it makes sex much more interesting, not quite what I expected!"

"Try and stop your pee midstream. That is your pelvic floor muscles. You need to tighten them regularly throughout the day just by tensing them up, holding it and releasing. Once you have identified the PFM, you can do exercises anywhere anytime."

The majority of the discussion around how women were first introduced to exercises 


\section{A DESIGN ETHNOGRAPHY OF PELVIC FLOOR EXERCISES}

revolved around identification of the PFM whether on the toilet, practiced and used during sex or generally practicing throughout the day. The importance of exercise alongside functional movement in everyday life was stressed by the health professionals as well as a need to instil awareness in patients of the effects that lifestyle has on the pelvic floor, similarly the women although not discussing "functional exercise" explained that practicing PFX alongside other daily chores was most efficient.

\section{PFX for Busy Schedules}

Respondents highlighted that there is a difficulty in performing PFX when women have a very busy schedule, particularly after birth. Many of the women's responses to a love letter to their PFX as part of the probe showed women's relationship to PFX is influenced strongly by their personal schedule. Additionally the women explained that they will be most likely to conduct PFX in comfortable spaces, convenient places and when alone. For example two women described that their relationship with their pelvic floor is at its best when:

"[I] am by myself or at least don't have a child on me such as in bed, or the shower or in the car."

"We are at our best together when I'm bored and stuck inside."

In order for women to practice PFX they expressed that they need to be in a comfortable or convenient space where they are alone, undisrupted or bored. For example women described the spaces that they practice PFX:

"To be honest I don't really do them consistently enough but do them while alone as it allows me to focus."

"[I]'ll explain as best as I can: 1) Out for a walk with the pram... mainly because if I'm exercising I might as well do everything; 2) In bed reading... it's quiet and I'm not distracted by little people; 3 ) at the computer... also purely when I get bored, I don't think doing PFX make me feel anything but maybe a little more productive."

"My lounge because it is the most convenient and comfortable place to do the PFX."

"I do my pelvic floor muscle practice when I pee, I've been told it's really important to do this and it's good practice to always do it. Sometimes I do my pelvic floor muscle 


\section{A DESIGN ETHNOGRAPHY OF PELVIC FLOOR EXERCISES}

exercises when I'm working at my desk. Other times, when it crosses my mind I do it while I'm driving."

"I do my PFX while sitting on my couch because when I do them here I feel relaxed. I do my PFX while laying on my bed because it is important to be comfortable. When I do them here I feel very comfortable. I do my PFX while sitting in my office because it's easy to do and I don't need to go out, hide or compromise my work for doing this exercise. When I do them here I feel I am committed to my well-being."

"Toilet: I do my PFX here because its quiet and I'm alone. When I do them here I feel good that I have remembered to do them. Couch: I do my PFX here because it's where I spend a lot of time. I feel annoyed that I have to do them."

Places and times in which women practice PFX were discussed to be one of convenience, comfort and also "alone time." Subsequently this can be foiled by distractions, the presence of other people and the busyness of daily life. The particular issue of women's lack of time was evidenced further in conducting this research, as several participants had to leave the study due to time constraints and commitments.

Health professionals emphasised the busyness and tiredness of postnatal women as a potential barrier to getting women to learn about and practice PFX, women themselves underscored busyness as a barrier to completing exercises and explained that exercises are best done "alone" or when "bored" in a "convenient and comfortable space." By identifying these needs there may be potential to design PFX devices which can be integrated into women's daily lives effectively.

\section{PFX for Pre and Postnatal Stages}

Approaches to teaching PFX are dictated by physical, cultural, and social factors. Due to tiredness and lack of time experienced by pregnant and postnatal women there is a right time for teaching the right type of PFX. In line with these findings Parkin highlighted that there should be further proactive engagement with women who have given birth including questions and further information about symptoms of PFD to aid women's awareness and treatment of the disorder successfully (Parkin, 2012, p. 31-35). 
A DESIGN ETHNOGRAPHY OF PELVIC FLOOR EXERCISES

Health professionals described how women's stage of pregnancy or postnatal stage may hinder their ability to practice PFX either with or without a device. Discussions with women and health professionals underscored that stages women go through from conception to postnatal recovery puts many stresses on women, in terms of physical and mental changes and lifestyle changes. The women's health trainer emphasised the importance of giving women advice and exercises suited to their stage of pregnancy. In the early post natal period exercises in isolation are described to be useful followed by functional exercise in the later postnatal stage.

For example the WHFC explained that during pregnancy the neuromuscular connection needs to be supported, so women need to be able to understand how their pelvic floor works and practice controlling or exercising it. Then in the early postnatal period they should be able to remember the information and exercises and start to practice PFX in isolation in the early postnatal stages to retrain the muscles and start to get the pelvic floor back to how it was before giving birth. Following this the WHFC explained that women can then move onto functional exercises. They explained it's crucial to teach women PFX before the later stages and post birth so information can be taken in and PFX understood before the "neuromuscular connection" is lost. This demonstrated that the stage of pregnancy women are introduced to PFX should correlate with the type of knowledge and exercises women are given if possible.

Similarly, other changes in pregnant and postnatal women's lives and bodies are considered as important when teaching PFX. The osteopath highlighted the importance of relaxation of the pelvic floor after 35 weeks of pregnancy, it was additionally suggested by the osteopath that the exercises in the bath or with a hypno-birthing $\mathrm{CD}$ can be useful for some women. This underscored a need for women to begin practicing relaxation of the pelvic floor before the birth. 
A DESIGN ETHNOGRAPHY OF PELVIC FLOOR EXERCISES

The physiotherapist did not highlight the above approaches but did express the importance of a full awareness of the needs of pregnant and postnatal women and their condition. The physiotherapist described that pregnant women are given exercises and advice, including help with posture, how to get in and out of chairs and beds, and help with sore sacroiliac joints caused by the relaxant hormone which enables your pelvis to move around more than normal. Literature such as Marques, Stothers, \& Macnab's, The Status of Pelvic Floor Muscle Training for Women emphasised that individual patients should have PFX programs designed specifically for them (2010). The programmes were explained to require; "clear instruction, motivation during therapy and scheduled follow-ups" (Marques, Stothers, \& Macnab, 2010, p 422). Women are given varying exercises and advice, at different stages of pregnancy and into their postnatal period. Each of these examples illustrates the changes pregnant women must deal with in relation to their pelvic floor, and importantly their connected core and body. The health professionals approached these issues and focused in different areas due to their professional specialisations.

The overall theme of Integrating PFX into Daily Life and the subthemes within it so far have highlighted that there is a need for women to understand the effect that their physical activities and lifestyle has on their pelvic floor and that functional exercises can be practiced when suited to the women's health needs.

\subsection{Device Concerns and Feedback}

Interviews with health professionals explored experiences with PFX devices and similar technologies as well as welcoming any comments or concerns about the future development of devices such as R-Leaf. However discussion of the benefits and possible concerns about the device were interspersed throughout the interview as health professionals 
A DESIGN ETHNOGRAPHY OF PELVIC FLOOR EXERCISES

seemingly found interest in discussing pros and cons of developing PFX devices such as Rleaf (described in the Introduction Chapter).

\section{Internal Device Concerns}

Health professional's experiences illustrated potential possibilities and barriers that they see in PFX devices based in experience with similar devices and/or with facilitating PFX. The health professionals showed they had varying experiences with PFX devices. Understanding of similar devices was strongest with the Physiotherapist who used PFX2 (2017) and NeuroTrac (2016) devices. NeuroTrac is the name of the brand and is used to describe a device they use. It was described by the physiotherapist to offer good feedback but is rarely taken home by women seeing a physiotherapist. The WHFC also demonstrated an understanding of and experience with similar devices such as Pericoach (Healthcare Professionals, 2016) and Elvie (2014-2017), it was described that women enquire after those devices and they were also discussed at a women's health conference. The osteopath however didn't know as much about similar devices but did highlight that there is a German made chair called the PelviCenter chair, at the CoreGood institute in Paraparaumu, Wellington, which diagnoses and treats pelvic floor issues in men and women. The PelviCenter chair is described to use electrical currents to enable activation of the pelvic floor muscles (PFM) (The CoreGood Institute, 2016). This does differ from a PFX device, but demonstrates knowledge of recent technological developments for PFD locally.

An insertable device was suggested to be an additional barrier for pre and postnatal women to completing their exercises. The physiotherapist explained that postnatal women find it hard enough to try and fit exercises into their day, so inserting a device may give a further barrier to conducting PFX. The fitness health trainer also emphasised that while some women may find it useful, women who are pregnant or postnatal are "generally over being 
A DESIGN ETHNOGRAPHY OF PELVIC FLOOR EXERCISES

poked and prodded." In addition to this, it was stressed by the physiotherapist that a device should not be used internally, six weeks after an operation, six weeks after giving birth or if there is an infection present. One woman in the follow up interview also explained she would not use a device until four weeks after the birth. Here it's illustrated that sensitivity to women's condition after birth is important in order to offer correct guidance that does not harm the women and to avoid further barriers to conducting PFX. The health professional's experiences with other devices and with teaching patients PFX informed these perspectives. For example the physiotherapist explained that putting devices in a draw and forgetting about them was something they had noted with patients. Money/cost of devices was also said to be a poignant issue for new mums.

In the first theme Safety and Professional Support I've identified that the concerns about a device have significantly overlapped with the value placed on professional diagnosis and guidance demonstrated by health professionals. For example it's been described that issues appear to arise if devices can't educate and offer women guidance. The physiotherapist explained she has concerns about devices not being used properly and gave a recent example of an issue with a woman using a PFX home device incorrectly. In a similar vein, the WHFC explained they would not direct a woman to a device directly, but advise them to see a physiotherapist to discuss symptoms and then devices. Reinforcing this Porrett highlighted that physiotherapists are seen as important in diagnosing women and teaching them PFX with palpation and feedback, perhaps because many postnatal women have trouble locating their pelvic floor muscles (Porrett, 2010, p29-30). These arguments were at the crux of the discussion with health professionals and frames concerns, questions and prompts they had for the development of a future PFX device. 
A DESIGN ETHNOGRAPHY OF PELVIC FLOOR EXERCISES

\section{Additional Device Feedback}

Other important ideas that were not recurrent themes, but nonetheless worthwhile suggestions include; concerns around radiation; especially for women carrying babies. It was highlighted by the osteopath that it will be important to show in the marketing of future devices for pregnant women that this has been taken into consideration.

Additionally a question for women about experiences with using apps for their health showed that only one woman used an app for her health. This is called Ovia (Ovia Health). Ovia is an app for overall health during pregnancy and includes "Ovia fertility', Ovia pregnancy" and finally "Ovia parenting" which was described by the respondent as "helpful for baby care" (Ovia Health). None of the other women used an app. However one woman highlighted she is open to the possibility, "especially if it involves reminders." The one woman that used an app for her health found it useful for all stages of baby care, showing that the technology that taught her about her health and body offered guidance and suited her other daily needs and interests. This gives an example of an app which works on many levels to suit the women's changing needs throughout pregnancy. And demonstrates that there is a need for devices to acknowledge the need to integrate into daily life by being able to bend to the women's needs, this reinforces the theme of Integrating PFX into Daily Life.

The main Device Concerns and Feedback theme gives insight into similar technologies already in use by respondents. Discussion and feedback of the pros and cons of existing or conceptual PFX technologies has also reinforced key themes throughout this chapter as exemplified above.

\subsection{Design Recommendations}

The design recommendations have been organised with four main headings that 
A DESIGN ETHNOGRAPHY OF PELVIC FLOOR EXERCISES

correspond with the themes discussed above. These main headings have three sub headings beneath them to clearly illustrate how this research can be used to offer direction for the development of future PFX designs such as, but not restricted to R-leaf. The recommendations below should be used to offer insight into important areas and spark further questions and lines of research.

\section{Safety and Professional Support}

The first introduction to the design should offer women an initial screening to determine if professional diagnosis is needed and the specific sort of guidance required for that woman.

Part One: Screening

Designs should have a screening process or direct women to a self assessment site such as the 'Pelvic Floor Screening Tool' Downloadable PDF from the Pelvic Floor First website which was discussed to be used by the fitness professional and physiotherapist (Continence Foundation Australia, 2014). Alternatively women may prefer to be directed to a professional clinician. Both options should be offered.

\section{Part Two: Diagnosis}

- If pelvic floor symptoms are found to be present during a screening, women should be referred by the device for professional diagnosis.

- At this stage women will require specific guidance and reassurance before booking a diagnosis. Information about appointments with health professionals, their role and pricings could give further support for women requiring a diagnosis.

- All women will benefit from a screening. Women that pass the screening with no 
A DESIGN ETHNOGRAPHY OF PELVIC FLOOR EXERCISES

symptoms should be given information regarding maintaining their pelvic floor health, and can still be offered guidance specific to their health and lifestyle.

\section{Guidance and Motivation}

- The design should inform women that it's common for the sensation of learning and practicing PFX to feel "strange", "weird" or "ticklish" at first. However it should be made clear that professional guidance is there to give support and to help women become familiar with what correct exercises feel like for them.

- The design should offer safety, guidance and information specific to the woman's condition. The women's condition will be clear once screening and/or diagnosis has taken place. Refer to the themes below within the design recommendations to see 1) A variety of metaphors suited to different learning styles and needs 2) How to aid women depending on her stage of pregnancy 3)When not to use a device for each woman. Further research of these areas with a professional would be beneficial for the development of a PFX design.

\section{Teaching PFX with Metaphor}

Part one of this section must be used first to educate and inform the women followed by part two if needed. The third subtitle gives an example of how the device may aid women who need to understand the holistic body and may aid understanding of the need for lifestyle modifications and functional exercises. The majority of these metaphors are connected to physical actions of the body and so the design should use visualisations that women can

connect to their bodies. To visually aid women when learning how to practice PFX a variety of metaphors can be used, as shown below. 
A DESIGN ETHNOGRAPHY OF PELVIC FLOOR EXERCISES

Part one: Visualising the Pelvic Floor

- The app should use a visualisation of the female pelvis in some form. It should teach women where the pelvic floor sits within the pelvis.

- A lift motion and squeeze motion within the structure of the pelvic floor can be shown to illustrate the action to be achieved, refer to Teaching PFX with Metaphor in the findings for specific examples of how the health professionals use their models, this can be used to guide the design.

\section{The Body in the Metaphor}

- If the woman needs further assistance, they can be offered further metaphors that may aid their practice. The design should test each metaphor with the woman to determine which works for her. These metaphors refer to familiar physical actions of the body.

Metaphors used by health professionals include, "stop your flow of urine to locate the pelvic floor muscles (never use this often as it can cause an infection)", "imagine you are squeezing around a tampon" and "imagine you are stopping the passage of wind."

Metaphors women would use include those mentioned above as well as: "imagine a plunger, or compare it to your diaphragm when doing deep breathing exercises" and "it's like tightening the lid on a bottle."

\section{Relaxing the Pelvic Floor}

- The design should also include metaphors for relaxing the pelvic floor. One example that can help women relax the pelvic floor is; the 'Silk scarf' visualisation: "Imagine a silk scarf is laying on the seat you are sitting on and imagine it wafting upward as you pull it up into the vagina. Then you drop it down again.” By imagining drawing 
A DESIGN ETHNOGRAPHY OF PELVIC FLOOR EXERCISES

the scarf up, you have an awareness of your muscles but then you focus on dropping the scarf down to relax the pelvic floor.

- The design could also encourage baths as a way to practice relaxation exercises alongside hypnobirthing soundtracks or draw from other relaxation techniques suitable to the woman's condition.

\section{Visualising the Holistic Body}

The design should illustrate the impact of physical activities on the pelvic floor. This may be inspired by visual images of a biotensegrity model and/or a rubber chicken. This is discussed in the findings under the corresponding title Visualising the Holistic Body. Pilates could also be used as a model of teaching women full body awareness through a connection with the core body, breathing and physical movements of the body. 
A DESIGN ETHNOGRAPHY OF PELVIC FLOOR EXERCISES

\section{Integrating PFX into Daily Life}

This next part in the narrative could be applied once women understand and can practice PFX in isolation (this may vary for different women). The design should work to make women aware of the impact that their lifestyle and physical activities has on the body.

They should be given support with lifestyle modifications and introduced to functional exercises if suitable for the women (this is based on the initial screening, diagnosis and guidance which is customised to the woman).

\section{Functional Exercise in Daily Life}

- The design should teach women functional exercises. This may not be suitable for some women, so this depends again on the diagnosis, as some women may need to concentrate on achieving PFX in isolation first. Refer to the corresponding theme, Integrating PFX into Daily Life for more examples.

- Functional exercises enable women to retrain their muscles to behave as they did prior to pregnancy. For example teaching women to engage their pelvic floor when lifting a baby, will aid women in the practice of retraining their pelvic floor.

- The design should offer reminders to the women based on their own unique timetables. It could be tied into something that they already do regularly to help them get it done as discussed by the osteopath.

\section{PFX for Busy Schedules}

The design should work to instil awareness in a way that fits into the lives of women. Women will practice in daily life in convenient and comfortable familiar spaces such as during, walking, office work, reading in bed and sitting on the couch. They seek reminders to aid them to do these exercises. Lifestyle modifications and functional exercise 
A DESIGN ETHNOGRAPHY OF PELVIC FLOOR EXERCISES

recommendations as well as reminders should be integrated seamlessly into each woman's schedule. These reminders could be shaped to suit the woman's lifestyle. For example the design could remind women it's time to read, have a break, or exercise and alongside this practice PFX. It may also encourage an awareness of exercises with and without the design, so that women develop their own awareness. Overall the design should offer customisation so that it can guide women in a way which suits their lifestyle, health needs and schedule.

\section{PFX for Pre and Postnatal Stages}

- The design should customise exercise types to suit the woman's diagnosis and stage of pregnancy.

- Refer to the subtheme PFX for Pre and Postnatal Stages in the findings to view the different advice that should be offered women at various stages of pregnancy. 
A DESIGN ETHNOGRAPHY OF PELVIC FLOOR EXERCISES

\section{Device Concerns and Feedback}

The design must be sensitive to the women's condition and consider the safety and convenience offered.

\section{Internal Device Concerns}

- The insertable device should not be a requirement for using the app. It could be optional. The device should give a warning of when the device should not be inserted as well as offer an option not to use the device even if the woman is able.

- Internal devices should not to be inserted if an infection is present, or up to six weeks following childbirth or an operation. Advice and information should be available about safety when using a device.

\section{Additional Device Feedback}

- Other issues such as addressing radiation in blue tooth and effects on the baby could be made available and should be checked when user design research is conducted.

- Design development should investigate other concerns of pregnant women around the design and any other barriers to using a device.

- Costs and pricing of the device should be suited to women's budgets. Further examination of this may be carried out as the design develops.

These design recommendations give insight into the experiences of professionals and pregnant and postnatal women. This insight will aid in guiding the development of future PFX designs. The recommendations give focused direction and refer viewers back to the findings. This is done not only to offer information but to offer a holistic image of the findings so that groups or individuals can view new recurring themes or be inspired and 
A DESIGN ETHNOGRAPHY OF PELVIC FLOOR EXERCISES

informed by all of the research presented. These themes connect in a variety of ways and should be used to spark ideas as well as questions. They may be used as a springboard for the future development of PFX designs as well as enabling further investigation, exploration and human centred research. The following Discussion chapter will draw on these findings and discuss them in the context of background literature. Namely the discussion will illustrate that an ethnographic research approach can be used to inform the development of a future PFX device on a micro and macro level and will highlight the strengths and weaknesses of this approach. 
A DESIGN ETHNOGRAPHY OF PELVIC FLOOR EXERCISES

\section{Discussion}

In the previous chapter the findings have been presented and design recommendations have been created as a list. This has been described to be a holistic image of experiences that can be used to inform the development of future pelvic floor exercise (PFX) designs by giving guidance. This may lead to further research, design development and spark questions and discussion. Ethnographic design research is used to explore emotional and social experiences in context which has enabled rich data and holistic outcomes to inform and inspire design (Nova, 2014, p. 34; Dijk, 2010). This chapter draws on this,discussing in detail how ethnographic design research works to inform the development of future devices on a micro and macro level. On a micro level, the findings offer insight into individual experiences and give actionable information for the future development of a PFX device. On a macro level, larger themes are illuminated, these themes are expanded on in this discussion with reference to the broader cultural issues discussed in the background chapter. These central themes are identified here as; education and empowerment and have been shown in the findings to be important to both health professionals and women.

The theme of 'education' demonstrates that women need to be educated and informed from the moment of learning PFX and for as long as women require support. Additionally, lifestyle, health and safety need to be facilitated through a versatile design so that future designs can be 'empowering' for women. These overarching themes demonstrate how ethnographic design research can inform the development of design through giving in depth insight into individual's experiences and discussing them as part of the larger social and cultural context. This chapter also addresses the strengths and weaknesses of an ethnographic design research approach in informing the future development of devices and illuminates spaces for future studies. 
A DESIGN ETHNOGRAPHY OF PELVIC FLOOR EXERCISES

\subsection{Overarching Themes}

The themes in the Findings chapter such as: Safety and Professional Support, Teaching PFX with Metaphor, Integrating PFX into Daily Life and Device Concerns and Feedback have been used to create corresponding design recommendations. Examination of the findings and design recommendations alongside previously discussed literature has revealed two overarching themes of 'education' and a need for consideration of 'empowerment' when seeking to aid women with PFX. These themes will be expanded on below with reference to relevant literature.

The need for education was highlighted throughout medical texts which had focused on female pelvic floor health (Kenton \& Mueller, 2006, Urinary Incontinence para 4; Almeida \&Arrigoni , 2014; Moossdorff-Steinhauser, 2015 ;Lagro-Janssen, 2012). A lack of treatment of pelvic floor disorder (PFD) also demonstrated further broad cultural issues in education and health with a need for further awareness and understanding of treatment from patients and physicians (Kenton and Mueller, 2006, Urinary Incontinence para 4; Almeida \&Arrigoni , 2014). This has been reinforced through my design ethnography research as women and health professionals have shown that there is need for education about the pelvic floor and awareness of pelvic floor symptoms and exercises.

This design ethnography research has revealed that there is a need for women to understand their own bodies in order to practice PFX. For example the metaphors that health professionals often used were most commonly attached to biological and health information so that women could understand their bodies better. This was done with a model of a pelvis which women could then relate to and visualise their pelvis and pelvic floor more clearly. The way that education is tied into the teaching of PFX and continued throughout women's practice of PFX is highlighted in the findings. There is potential through a device and app for 
A DESIGN ETHNOGRAPHY OF PELVIC FLOOR EXERCISES

education to be incorporated into the narrative of the system. For example the design recommendations emphasise that women will have already undergone a screening or professional diagnosis before learning PFX. This enables them to be properly screened and also allows them to learn about their own pelvic floor health. Women who do not have PFD symptoms, will still benefit from a screening and should be given information regarding maintaining their pelvic floor health. Women can also be given information of how their pelvic floor is affected by their personal daily activities and offered guidance with lifestyle modifications and the right exercise plan for them. This information can be incorporated into future PFX facilitating devices which will help to guide the narrative of the system. This research may also inform the interface of the app. as images based on popular visual ways of teaching can be used to help to guide women through their exercises. An interface and system that teaches women about their bodies and offers information specific to that women will be responding to a key issue. The design should be aware of how education and awareness may facilitate health professionals and women to understand PFX and specific women's needs.

Previous similar studies have also underscored the importance of using design ethnography research for the development of healthcare and describe that all healthcare devices should 'empower' the user. Empowerment is used as a goal in various human centred design research approaches in healthcare, and entails the aim of understanding perspectives of the user; patient or clinician, so that design development can strive to facilitate emotional, social and cultural needs without fostering dependence on technology (Hirsch et al, 2000, p 5; Gordon, 2014, p. 60-73;Crabtree et al, 2003, p. 2). The findings of this study reflect this knowledge. For example this study explores women's experiences alongside health professional's recommendations and knowledge which can guide future PFX designs to be 
A DESIGN ETHNOGRAPHY OF PELVIC FLOOR EXERCISES

developed with awareness and sensitivity to key themes and issues. Specifically, health professionals highlighted that women should have an awareness of how to protect and strengthen the pelvic floor during everyday activities. While women did not display any knowledge of this they did underscore that exercises are most commonly done alongside daily activities. This highlights a potential for exploring how women can be supported in practicing PFX as part of everyday life, in a way that encourages an 'awareness' of their pelvic floor. Concepts such as Pilates and biotensegrity discussed by health professionals adopt a holistic approach to health, which may be used as a model to inform assisting devices and empower women through giving them an awareness of their bodies that extends to their life both with and without an app and/or device. For example lessons from the device may be taken away with women in their daily lives, with the device being returned to, to 'log' progress or receive further motivation and insight into their health. These findings show how insight into experiences and knowledge of women and health professionals is crucial as it offers information that can shape the development of a device so that it can facilitate and encourage women to be empowered through use of the system.

It's also been discussed in previous similar studies that it is important to look to the negatives that the design may evoke, such as anxiety surrounding the disorder or health issues and the inability of individuals to use technology due to lack of knowledge or implications with their current condition (Hirsch, 2000, p1;Caffazzo;2012 ,p10; Furniss, 2014 p1). It's described that understanding the user's needs and designing in a way which facilitates and empowers individuals is crucial. Extending on this knowledge, an important theme in the findings and design recommendations is that there are situations in which women should not use an insertable device, such as when an infection is present or six weeks after giving birth or having an operation. It was also discussed that women may not want to insert a device after giving birth and women are often so busy that taking time to insert a device could be a 
A DESIGN ETHNOGRAPHY OF PELVIC FLOOR EXERCISES

possible barrier to completing the required PFX. The recommendations for design therefore highlight the importance of offering women help with exercises with the option of practicing without an internal device. By using the experiences of individuals to uncover these themes information is offered that can enable future devices to be aware of factors that may facilitate and debilitate women. In terms of design this means tailoring the app to suit each woman's condition and giving awareness and safety warnings about using an insertable device as well as giving an option to use, or not to use the internal device.

The themes of education and empowerment presented above show how design ethnography research can be used to inform the development of future PFX designs on a micro scale. These two themes are discussed below with reference to their larger social and political context and how this can help to inform the development of future PFX designs on a macro level. Design ethnography research offers guidance, but also gives the opportunity for exploration and discussion of broader social and cultural issues. Xue emphasises that there is a call for women's healthcare technologies that aids individuals not only in terms of 'health' in the short term but to create a 'meaningful' design that has the potential through individuals everyday interactions and experiences to offer 'empowerment' or 'change' for women as a whole (Xue, 2009, p.80, 130). Feminist literature and references to female healthcare history gives strong background to this discussion. Culture and context has been shown in history to influence the form of cure or medical treatment (or more commonly 'lack of') for pelvic floor issues, this alters women's and health professional's experiences and perceptions of the female body and female health (Gordon, 2014, p.19-21). Everyday activities influence and are influenced by large scale social and cultural contexts for women (Porrett, 2010, p.194). Young took a phenomenological; stance and postulated that the structures of culture can be

shown to have influenced the female body and perceptions of it (Young, 2005, p.17). To extend on this further Highmore's (2002) discussion of "the personal is political" in Everyday 
A DESIGN ETHNOGRAPHY OF PELVIC FLOOR EXERCISES

Life and Cultural Theory describes that feminisms, "emersion in the everyday (domestic routines, sexual identity and so on - neatly designated by the slogan the 'personal is political') should alert us to the potential of the everyday to generate new political forms" (p.28). PFX are shown in the results to be an activity associated with frequent practice that can be done alongside daily events. The design has the potential to become part of women's everyday lives. From this place of influence it can seek to foster a sense of empowerment in women by offering women knowledge and understanding within and of their own bodies. Knowledge within their bodies comes from learning the correct exercises, this is shown in the findings to be intertwined with information and education about their pelvic floor and condition as illustrated above. Design ethnography has given attention not only to how individual's experiences can inform the physical development of design but also to the larger issues that the design development of future PFX designs should be aware of.

Design ethnography research has reinforced key themes in previous literature and given a new in depth perspective that can help to inform the development of a future device. The importance of human centred research has been highlighted showing that attention to what the patients want should enable technologies to be aware of needs and even barriers that devices may create. This study has illuminated issues which the design may face in facilitating women, this can inform the device so it may be designed with awareness and develop versatility. By examining the findings in the context of background literature we also see the importance of acknowledging the larger social and cultural issues of education and a need for empowerment which the device should seek to address. 
A DESIGN ETHNOGRAPHY OF PELVIC FLOOR EXERCISES

\subsection{Methods Discussion}

Here, the impact of specific methods adopted in this study are discussed with reference to previous literature. It is illustrated what the intention of the method was and what it gave way to. The strengths and weaknesses of probes and semi structured interviews found in this study will be discussed in more general terms in the final section of this chapter.

\section{Recruitment}

It's important to understand the perspectives of women in designing healthcare designs and systems to assist them. The interviews with health professionals added a foundational reference point for further discussion of teaching PFX and the perceived experiences of women, as well as offering invaluable medical insight. This study maintains a focus on women who live in two of New Zealand's cities; Auckland and Wellington. The respondents were recruited if they were pregnant or in the postnatal stage and lived in New Zealand and were aged either in their 20's or 30's. In future research attention should be paid to the demographic to ensure that women of all areas, situations and circumstances are given equal opportunity to help shape the future development of designs which are aware of their needs, understandings and experiences. Previous studies such as Gordon (2014) have underscored the importance of awareness of all demographics of 'users' ( $p$ 27). In a similar vein Xue emphasises the importance of understanding a variety of women's sociodemographic backgrounds and perceptions in order to design for female healthcare (Xue 2009, p. 130-132). The recruits in this study included women and health professionals and no specific sociodemographic was focused on, as the aim of this study was to recruit women thorough purposive sampling and the snowballing method (Schutt 2012, p157-8), and to initially explore experiences of both health professionals and pregnant and postnatal women which could lead to further study, questions and design development. 
A DESIGN ETHNOGRAPHY OF PELVIC FLOOR EXERCISES

\section{Metaphors}

Metaphors are often used alongside anatomical knowledge, communicating physical experiences and any social or cultural understandings connected to pelvic pain (Grace \& MacBride-Stewart, 2008). Additionally, metaphors are shown to be commonly used by health professionals to teach PFX for example the Pelvic Floor First website, (used and promoted by health professionals in this study), gives examples of ways you can learn PFX and uses "visualisations" as one of the tools (Continence Foundation of Australia, 2016). The examples given on the website emphasise a squeezing and the use of body focused metaphors to teach PFX, such as "squeeze in the muscles around the vagina and suck upwards inside the pelvi[s]" (Continence Foundation of Australia, 2016). This reinforces the way visualizations have been shown in the results to be effective when connected to the body. Visualisations are a crucial part of women trying to understand and learn about how to practice PFX. Interestingly, like a qualitative study of 40 New Zealand women by Grace and Macbride (2008) the metaphors have been used alongside anatomical knowledge, communicating physical experiences, in this study this demonstrates the value held in education about the body to facilitate PFX. This method could be applied in other instances where physical actions cannot easily be seen. It is a useful method to employ in a healthcare context and can result in a collection of useful metaphors that may not only inform but inspire design development.

\section{Photos}

The photo's and accompanying written prompts gave space for women to reflect on their daily lives and where they practice PFX. Hirsch's previous study has made use of a 'log book' as well as a camera to understand how people feel and find gaps for design (Hirsch et al, 2000,p.2). However, no women provided any personally taken photos of their 


\section{A DESIGN ETHNOGRAPHY OF PELVIC FLOOR EXERCISES}

environment and instead chose the option to write about it. This perhaps highlights that giving respondents an option to write or take a photo can at least offer a way of communicating in the way that suits them. The added discussion of how they feel when they practice in that space gave further insight into how PFX make women feel. Information from this reinforced women's busy schedules and that they are more likely to practice in comfortable places that are convenient in terms of time.

\section{Letters}

A variation on Gerber's love letters (2011, p.143) was used to give women the chance to reflect on their feelings on their own. This task worked well, however the decision to include 'sentence starters' so that a blank page would not scare women from writing, may have been a factor in the shortness of some of the contributions. However, I can only deliberate on the cause of the shortness of some responses; the prompts did still enable all women participating in the probe to give responses. Further research and even experimentation on the researcher's part of the best way to prepare a letter for respondents may be beneficial in future work.

\section{Narrative Analysis}

The thick data accumulated through interviews and probes required an open and flexible method of analysis. As this study is based on the experiences or stories of individuals, narrative analysis has worked well for grouping themes and describing the findings. However, further discussion surrounding the use of analysis methods for design research in an academic context would be useful. Nova contributes to this greatly highlighting the "AEIOU" method as a recognized way of analyzing ethnographic design research data (Nova, 2014, p.54). Although this method is not accepted as an academic methodology of analysis (Nova, 2014, p.54) which resulted in adoption of a narrative analysis 
A DESIGN ETHNOGRAPHY OF PELVIC FLOOR EXERCISES

approach. Although ethnographic design research is relatively newly established in academia as an investigative tool in the field of study, there needs to be more weight on what is to be done with the findings and how the 'sorting' of data can best be aligned with an analytical methodology. Perhaps narrative analysis offers a first option; a substantial contribution by Gazan highlighted the benefits of narrative analysis for informing the design of library systems, which is a useful starting place (Gazan, 2005).

\subsection{Design Ethnography Research; Lessons Learned}

Previous medical studies have given an invaluable insight into pregnant and postnatal women's experiences with PFX and PFD symptoms (Moossdorff-Steinhauser et al, 2015; Lagro-Janssen, 2012). However, these studies work to inform medical staff and systems whereas this ethnographic research approach is specifically tailored to inform the development of future designs. This design ethnography research to inform design is presented in a thesis form utilising methods of a literature review, probes, semi structured interviews and narrative analysis. The ethnographic design research has formed findings, design recommendations and this discussion. Each of these aspects inform the future development of a PFX device by: 1) presenting holistic outcomes in the results 2) underscoring their significance to a device through design recommendations and 3) discussing the findings in the context of the broader social and cultural issues the device seeks to address. These outcomes are illustrated previously. Here I will discus, in the context of similar papers, the strengths and weaknesses of the design ethnography approach taken and how this work can be extended on in the development of future PFX designs.

\section{An Adaptable and Open Approach}

The need for further development of research with a human focused approach in healthcare design has previously been highlighted (Xue, 2009; Crabtree et al, 2003, p.1; 
A DESIGN ETHNOGRAPHY OF PELVIC FLOOR EXERCISES

Hirsch et al, 2000, p. 2; Savage, 2000, p.1). More specifically, exploring user needs in a “sensitive setting” is a largely underdeveloped area (Hemmings, Crabtree, \& Rodden,, 2002). It's been emphasised that methods should be shaped for suitability to the context of each individual project (Crabtree et al, 2003, p.1; Xue, 2009; Hirsch et al, 2000, p 2). Design ethnography research methods in this study were used to understand and explore current experiences with teaching, learning and carrying out PFX.

The similar studies that used human centred research to inform healthcare design had different approaches to each other and to this research. For example some used the research done to create themes to inform design (Hirsch et al, 2000) others had teams which circulated through stages of design research, design development and user design (Cafazzo et al, 2012).

Similar studies to this one had approaches which were shaped to suit the phase of the design project, number of researchers or the expertise of the team and the length of time the study was given. This meant that the methods and the outputs were different. For example Furniss et al aimed to develop and pilot a design for user testing this included user design research, the team's research was strongly connected to the rapid development of design ideas and quickly moved through phases from initial research to design development. (Furniss et al, 2014).

However, my project sought to inform the design at its early stages through design recommendations, findings and the discussion to give further context to the issue it addresses. To aid the development of the PFX device R-Leaf and similar future devices, it was important to keep my initial ethnographic fieldwork open, like Hirsch et al. For example Hirsch et al described their methods as 'broad based ethnographic methods' this research was formulated by a team of designers and social scientists and lead to significant social, emotional and cultural themes to inform designs for eldercare (Hirsch et al, 2000). Adopting 
A DESIGN ETHNOGRAPHY OF PELVIC FLOOR EXERCISES

a similar approach meant that an understanding of elements that make up women and health professionals experiences could be understood. For example, an open approach is a key aspect of an informational probe, which is used in early stages of design development to openly explore the field (Mattelmäki, 2005, p. 88). Through this method and semi structured interviews, insight into the experiences of women and health professionals with PFX was given.

This approach focused on an exploration of experiences with PFX and lead into questions about existing and/or imagined interactions with PFX technologies. This worked well with health professionals, because by reserving a space for discussion of devices at the end we could first explore openly the experiences health professionals have with treating women, then move into their experiences with similar devices and finally their comments and concerns regarding future PFX devices such as R-Leaf. This helped to give space for existing experiences and knowledge to be explored to inform the future development of PFX designs.

Informing the development of the design was key in this project, so like Cafazzo et al in relation to the themes found from fieldwork and analysis, design responses were written. In Cafazzo's case these were included in the development of a pilot design which lead to further testing and design responses and guidelines (Cafazzo et al, 2012). In my study, information gathered from the probe and interviews has set up useful areas for design development and cast a light on further areas that could be explored throughout the design process. 
A DESIGN ETHNOGRAPHY OF PELVIC FLOOR EXERCISES

Focus on Stories of Experience

As explained above an open approach to understanding the experiences of individuals was the primary focus in this design ethnography research. However, this study also included questions about technology, this was a step towards understanding individual's knowledge and relationship with similar technologies and has informed the design recommendations and discussion above. Questions relating to the use of similar technologies were included in both the health professionals semi structured interviews and into the probe itself. Based on what's been suggested by previous similar studies, a focus on designs and interactions already playing a role in individuals lives can help to create an awareness of how various technologies may lessen, or strengthen, the stigma of a health issue (Hirsch et al 2000, p.5; Gordon, 2014 ,p.60-73). In my study, for example, the inability of some women to insert a device due to recovering from child birth or an operation was discussed, and the findings revealed that only one woman was familiar with using an app for her health. These initial findings illuminate experiences or a lack of experiences of devices, as well as highlighting concerns and giving constructive feedback. However, there could be further investigation of the barriers and assistors' technology may offer women to extend on what's already been found and to understand in more depth the use of devices in context. For example, it's been emphasised that user design research has been required in similar studies to fully test usability and ease of use of designs for health professionals (Hirsch et al, 2000, p.5; Furniss et al ,2014 , p.62; Gordon,2014, p. 22-23 ; Xue, 2009, p.28- 34). Further exploration of the role of healthcare technology can therefore be best explored through 'user testing' which can be applied as future devices are developed further. This highlights that how women may interact with such a device will be best explored through women using a device in context. 
A DESIGN ETHNOGRAPHY OF PELVIC FLOOR EXERCISES

Time

Time is a broadly accepted issue encountered in ethnographic fieldwork often due to the time taken in gaining ethics approval and the issues of time related to the unpredictable nature of fieldwork (Savage, 2000, p.2-4). A weakness of probes in general is that sometimes they may not be returned or completed (Crabtree et al, 2003; Hirsch et al, 2000). In this instance out of the twenty probes sent we had just six responses, the response rates varied from within the same day to a matter of months later. In this instance the time taken to gain ethics approval was predicted and worked around. However, health professionals and pregnant and postnatal women proved to be very busy, resulting in significant delays in interviews and probes, meaning that information collected was not discussed in depth with respondents. Due to the open nature of questions and probes, design ethnography research is highlighted to have potential to lead to new interpretations and unique responses so data can be misunderstood (Mattelmäki, 2005). To counterbalance this, questions were sent out to women targeting any aspects of their probe responses which were not clear, this enabled women to expand on and give clarity and strength to their perspectives and thoughts. On reflection of the time frame of this project and information found it could have been beneficial to focus on just one of the groups, perhaps giving time for more in depth discussion with one group rather than initial research with two. However the findings from both groups have revealed some unique insights and offered a breadth of information which will be useful for this project. Overall, the time delays have not negatively impacted the overall research but doubtlessly have shaped it. 
A DESIGN ETHNOGRAPHY OF PELVIC FLOOR EXERCISES

\section{Literature and Bias}

This thesis was completed to inform the future development of a PFX device, R-leaf and subsequently other future PFX facilitating devices, designs and systems, it was also written to fulfil requirements for gaining a masters degree. Tools such as a literature review, methodology and this discussion has significantly shaped the output of this project and demonstrated how design ethnography research can inform healthcare devices through exploring experiences and also through discussion of these findings in the context of other literature.

Additionally, discussion of the findings with reference to a social history and feminist literature reveals aspects of the larger issue which future PFX designers should be aware of. This not only gives actionable recommendations for the future development of PFX designs but informs it of the impact the future design could have and the overarching themes of the issue. Gordon's research offers a similar approach as he underscores the social history of 'incontinence' and uses this knowledge to discuss his fieldwork and how this can inform his design and future designs for incontinence (Gordon, 2014).

Ethnographic design research is useful not only for understanding the user, but it is also a tool for addressing broader global, social and cultural issues (Muratovski, 2010, p.377378). The overall findings can be used to reframe design questions and enable the design to be developed with an awareness of the context it is seeking to aid. However this approach should acknowledge bias. It must still be acknowledged that as with any planning, execution and discussion of ethnographic design research, it is shaped by the researcher and what is said and not said can be impacted by the presence of the researcher. I want to make very clear the "subjective nature" of design ethnography, the findings do not give facts but thick data which seeks to give felicitous insights into the perceptions and experiences of others (Goodson \& 
A DESIGN ETHNOGRAPHY OF PELVIC FLOOR EXERCISES

Vassar, 2011, 'Limitations of ethnography'). However, as discussed, this research makes use of academic literature and discusses overarching themes alongside relevant social and historical context so the outcomes presented can be understood on many levels and will help to inform the development of future PFX devices on a micro and macro scale.

This section has examined the role of design ethnography in informing the development of a PFX device. It has considered the strengths and weaknesses of this approach and acknowledged spaces for design development and for future study. This chapter also highlights the breadth this research has achieved through an open approach and through the academic context that the methods and discussion of the results are grounded in. However it's also underlined that in addition to the initial work conducted in this study further examination of individuals experiences with PFX technology will be crucial in understanding strengths and limitations of technology in context. Subjectivity is also acknowledged which again reinforces the importance of a broader understanding of the social issue through background literature.

Overall this research reinforces a need to educate women about PFX and the need for healthcare designs to empower it's users, this was discussed previously. However, design ethnography research has given a new perspective of these areas which can inform PFX design development. Ethnographic design research informs the device on two levels, a micro and macro level, on a micro level the device is informed of individual's experiences which have been transformed into design recommendations giving actionable guidance. However on macro level this research gives a broader context through an academic discussion of the findings and encourages further exploration, development and questions so that the device can address the larger social issue with sensitivity and meaning. Ethnographic design research within this study works by exploring experiences and then discussing the findings within a broader social context. In this sense it is crucial to remind the reader that design 
A DESIGN ETHNOGRAPHY OF PELVIC FLOOR EXERCISES

ethnography is not only the act of investigation but also the compiling of methods and the writing of results and discussion. The strengths and weaknesses of this approach have been discussed all of which have shaped the project overall. In the concluding chapter I will argue that ethnographic design research can be used to inform the development of future PFX devices on a micro and macro level through the use of design recommendations, in depth findings and a discussion. I will also underscore the need for further similar research to inform the future development of healthcare designs. 


\section{A DESIGN ETHNOGRAPHY OF PELVIC FLOOR EXERCISES}

\section{Conclusion}

This chapter underscores that ethnographic design research can be used to openly explore the experiences women and health professionals have with pelvic floor exercises (PFX), and argues that such research can inform the development of future PFX devices on a micro and macro level. I will also underscore the need for further human centered research which aids the development of healthcare designs, especially initial research that focuses on an exploration of experiences and the broader social context.

In previous medical studies PFX has been shown to prevent or resolve pelvic floor disorder (PFD) symptoms (Boyle et al 2012; Moossdorff-Steinhauser., 2015; Dawood, Jackson, \& Price, 2010). A major issue is that women do not conduct the required amount of PFX during pregnancy and after giving birth and are often conducting exercises incorrectly (Mason et al, 2010, Moossdorff-Steinhauser et al, 2015; Lagro-Janssen, 2012). This puts women at high risk of experiencing PFD symptoms (Mason et al, 2010, MoossdorffSteinhauser et al, 2015; Lagro-Janssen, 2012), which are debilitating in terms of physical and mental health and when ignored can worsen over time (Haylen et al 2009, p.7; Porrett, 2010,para 3.2.2), this demonstrates that facilitating women with PFX is highly valuable. Future PFX facilitating designs such as R-leaf seek to aid this issue and should be developed in a way which contributes to female health equality. Xue reinforces this and explains that we must look to develop healthcare designs with a strong awareness of the experiences of women (2009). Through ethnographic design research, this study has enabled an open ended exploration of women and health professional's experience and knowledge of learning, teaching and practicing PFX.

The findings of this exploration have been split into themes such as; Safety and Professional Support, Teaching PFX with Metaphor, Integrating PFX into Daily Life and 
A DESIGN ETHNOGRAPHY OF PELVIC FLOOR EXERCISES

Device Concerns and Feedback. The first theme shows there is a need for professional screening, diagnosis and support in the form of guidance of how to practice PFX correctly. The second theme demonstrates how knowledge of the pelvic floor and body can aid women's knowledge of PFX. Thirdly, Integrating PFX into Daily Life underscores the need for functional exercise as part of daily life, lifestyle modifications, and exercises which are suited to women's busy lives. And the Device Concerns and Feedback describes concerns health professionals have around an insertable device as well as drawing on a selection of device feedback comments. How these findings can inform the future development of PFX designs was demonstrated further in the corresponding design recommendations. The design recommendations highlight key themes and encourage designers to see possible directions for future design development.

Discussion of these findings using background literature also gave crucial context to this study, underscoring overarching key themes of education and empowerment which future PFX designs should embrace. The methods used for this project were chosen and adapted to suit the specific aims of giving insight into the practice, teaching and relationship women have with PFX. To form open and exploratory methods in this study there was a focus on the experiences women already have with PFX and the barriers or assistors to practicing PFX that come about in daily life. Informational probes (Crabtree et al, 2003, p. 4) enabled women to reflect privately on their relationship with PFX and provided insight into their lives and perceptions. Semi structured interviews with health professionals also provided an exploratory approach to understanding the experiences and strategies of teaching PFX.

Additionally, this thesis addresses a call for further human centered research for female and general healthcare design (Crabtree,2003, p1; Xue, 2009; Hirsch et al, 2000, p. 2; Marques, Stothers, \& Macnab, 2010). It's been shown in this thesis that design ethnography research offers a way to explore experiences, collate and present them, and also offers 
A DESIGN ETHNOGRAPHY OF PELVIC FLOOR EXERCISES

designers a macro and micro perspective of large cultural and social issues. Human centered research for healthcare design such as Furniss et al (2014) demonstrates that use of a pilot design to conduct human centered research can directly inform healthcare designs physically. In order to inform the physicality and design of healthcare devices to suits user needs it's been suggested that user centred design or similar research with a focus on users interaction with healthcare designs should be applied in final stages of design development (Hirsch et al, 2000, p.5 ; Furniss et al, 2014 , p.62; Gordon, 2014, p. 22-23;Xue, 2009, p.28- 34). However, in this thesis I stress that research which focuses on exploring contexts and experience is an imperative grounding for design development, especially when dealing with complex social problems. Papers such as Gordon's, UNMENTIONABLE: Socio-Structural Discrimination of Incontinence; Engendering Dignity by Design (2014) is an invaluable contribution to this field. Gordon presented an initial exploration of the issue with an ethnographic design focus and discussed the findings in terms of a social and cultural history, this gave a foundation for his own subsequent 'incontinence shorts' design (Gordon, 2014). This example reinforces Muratovski's postulation that design ethnography research is useful in not only giving information that can shape the physicality of the design but can help designers address large, or even overwhelming cultural and social issues (2010, p. 377-378). In this thesis, how PFX is taught, learnt, and experienced has been explored with a strong social, cultural, and human centered focus. In doing so specific facets of this larger issue, such as a need for designs to empower women and offer education, have been illuminated.

These overarching themes of education and empowerment have been identified in this thesis and discussed. The theme of education reiterated a ubiquitous call for the promotion of knowledge about PFX and the pelvic floor (Kenton \& Mueller, 2006, Urinary Incontinence para 4; Almeida \& Arrigoni, 2014; Moossdorff-Steinhauser et al, 2015; Lagro-Janssen, 2012). Similarly, in this study, the need for education was reinforced and extended on, as it 
A DESIGN ETHNOGRAPHY OF PELVIC FLOOR EXERCISES

was discussed that the practice of PFX itself should include education and information so that women can better understand their own health and body to practice PFX effectively. This discussion not only shows that education is crucial to facilitate women but also gives recommendations of how education could be implemented and built into the development and design of future PFX systems. The theme of empowerment was also widespread throughout previous literature (Hirsch et al, 2000, p. 5; Gordon, 2014, p. 60-73;Crabtree et al, 2003, p. 2; Xue, 2009) and reinforced in discussions with respondents showing that the way women are taught PFX should be suited to each women's health condition and lifestyle, so that they may be given safe and appropriate guidance that will empower them.

The discussion of the design recommendations also highlights further questions and pathways for research. For example, the design recommendations described that there should be an option for women to avoid the use of an insertable device. The discussion illuminated that this ability would enable future systems or designs to work towards tackling an overarching issue of the need for designs to empower women through flexibility and sensitivity to women's condition and preferences. This key insight has brought about further questions such as: How can women be empowered by a device which facilitates their practice of PFX? How can designs be developed to enable women to practice PFX alongside their existing schedule?

One further example, with regard to the overarching theme of education described in the discussion, illustrates a need to offer women information about their pelvic floor health which they can take with them into their daily lives. It's been shown that an awareness and understanding of the role of lifestyle and physical activities on the core and pelvic floor, is needed. This theme has shown in the findings that Pilates or even other similar practices like antenatal exercises could be used as inspiration for future designs to teach women a full body awareness that continues through their lives. Possible design questions here include: How can 
A DESIGN ETHNOGRAPHY OF PELVIC FLOOR EXERCISES

Pilates and similar holistic teachings be used as inspiration for a PFX facilitating design? How can the design of an interface or insertable device promote a holistic understanding of the body? And how can design integrate seamlessly with the routines of women's lives while empowering and educating them? This research can lead to further questions such as these, by restating the questions as design challenges a meaningful and socially aware PFX design can begin to be developed. Innovative and creative research methods should continue to address this issue by exploring the experiences of women and health professionals and discussing this in the context of previous social history and the growing body of similar literature.

When designs seek to tackle a complex issue in order to facilitate the health of individuals, then the context of that issue should be examined on a micro and macro scale. Rittel and Webber (1973) stated; "one cannot understand the problem without knowing about its context" (p. 162). I sought to explore the context of this issue and can now say that this research has created a better informed picture of the problem and people being designed for. This paper can be used to foster understanding, stimulate thought and questions as well as guide further research for the development of future PFX designs. 
A DESIGN ETHNOGRAPHY OF PELVIC FLOOR EXERCISES

\section{References}

Almeida, T. and Arrigoni,G. (2014). Subjective Epistemologies: Inconsistent Artefacts in the ReDesign of Medical Devices. Culture Lab Newcastle University.

Blackwell, A. (2006). The Reification of Metaphor as a Design Tool. ACM Transactions on Computer-Human Interaction, 13 (4), 490-590.

Bower, W. (2008). Overactive Pelvic Floor Muscles and Related Pain. K. B. Baessler (Ed.), Pelvic Floor Re-Education. London: Springer London.83-88.

Boyle, R., Hay-Smith, E. J., Cody, J. D., and Mørkved.S. (2012). Pelvic Floor Muscle Training for Prevention and Treatment of Urinary and Faecal Incontinence in Antenatal and Postnatal Women. Cochrane Database of Systematic Reviews.(10).

Brubaker, R. (2008). Muscle Function and Ageing. Pelvic Floor Re-Education. Baessler, K., Burgio, K.L., Norton, P.A., Schüssler, B., Moore, K.H., Stanton, S.L. (Eds.), 49-61.

Cafazzo. J., Casselman. M., Hamming. N., Katzman. D., Palmert. M. (2012). Design of an mHealth App for the Self-management of Adolescent Type 1 Diabetes: A Pilot Study. J Med Internet Res.14 (3).

Cambridge University Press. (2017). Dictionary. Retrieved 04 19, 2017, from Cambridge Dictionary: http://dictionary.cambridge.org/us/dictionary/english/pilates

Chiarelli,P.Murphy, B., Cockburn, J (2003). Women's Knowledge, Practices and Intentions regarding correct Pelvic Floor Exercises. Neurourology and Urodynamics. 22 (246),249. Neurourology and Urodynamics. 249.

Connelly, M and Clandinin, J.D. (1990). Stories of Experience and Narrative Inquiry. American Educational Research Association , 19 (5), 2-12.

Continenece Foundation of Australia. (2016). Women. Retrieved 04 18, 2017, from Pelvic Floor First: http://www.pelvicfloorfirst.org.au/pages/pelvic-floor-muscle-exercisesfor-women.html. 
A DESIGN ETHNOGRAPHY OF PELVIC FLOOR EXERCISES

Continenece Foundation Australia. (2014). Pelvic Floor Screening Tool for Women.

Retrieved 04 18, 2017, from Pelvic Floor First:

http://www.pelvicfloorfirst.org.au/data/files/Pelvic_Floor_First/Pelvic_Floor_Screeni

ng_Tool_for_Women_2014.pdf.

Cook, M. (2011, May 05). Story: Womens Health, Womens Health Activism 1840-1940. Retrieved 09 05, 2016, from Te Ara The Encyclopedia of New Zealand, from http://www.teara.govt.nz/en/womens-health. 1-10.

The CoreGood Institute. (2016). The Pelvicenter. Retrieved 05 03, 2017, from The CoreGood Institute: http://coregood.co.nz/treatment-options/pelvicenter/\#independant-study

Crabtree, A., Hemmings, T., Rodden, T., Cheverst, K. Clarke, K. Dewsbury.G.,Hughs.J., Rouncefeild.M. (2003). Designing with Care: Adapting Cultural Probes to Inform Design in Sensitive Settings. Equator IRC And Dependability IRC, 8. , 4-13.

Dawood, R., Jackson, S. R., and Price, N. (2010). Pelvic Floor Exercise for Urinary Incontinence: A Systematic Literature Review. Maturitas , 1-7.

De Lancey, J., and Wei, J. (2008). Functional Anatomy of the Pelvic Floor and Lower Urinary Tract. Clinical Obstetrics and Gynecology, Research Gate , 3-17.

Dijk, G.V. (2010). Design Ethnography: Taking Inspiration from Everyday Life. Service Design Thinking Publication, BIS Pub.1.

Elvie. (2014-2017). Elvie. Retrieved 11/4/2016, from https://www.elvie.com/

Furniss, D., Okane, A., Randall. R., Svetlena. T. , Mentis, H., Blandford.,A. (2014).

Fieldwork for Healthcare: Case Studies Investigating Human Factors in Computing Systems. Toronto: Morgan and Claypool Publishers.

Gauntlett, D. (2015). The LEGO System as a Tool for Thinking, Creativity, and Changing the World, in Making Media Studies: The Creativity Turn in Media and Communications Studies. In D. Gauntlett. New York: Peter Long. 
A DESIGN ETHNOGRAPHY OF PELVIC FLOOR EXERCISES

Gaver, W., Dunne, A., and Pacenti, E. (1999). Design: Cultural Probes. Retrieved 11 05, 2016, from, Research Gate:

https://www.researchgate.net/publication/220383091_Design_Cultural_Probes

Gazan, R. (2005). Imposing Structures: Narrative Analysis and the Design of Information Systems. Library and Information Science Research 27 , 346-362.

Gerber, E. (2011). Tech Break Up: A Research Method for Understanding People's Attachment to their Technology. Proceeding CandC '11 Proceedings of the 8th ACM conference on Creativity and Cognition, 137-145.

Goodson, L., and Vassar, M. (2011). An Overview of Ethnography in Healthcare and Medical Education Research. JEEHP .

Gordon, B. C. (2014). UNMENTIONABLE: Socio-Structural Discrimination of Incontinence;Engendering Dignity by Design. New York, Rochester: UMI Dissertation Publishing.

Grace, V and MacBride-Stewart, S. (2008). Metaphors of Injury;Women make sense of Pelvic Pain. T. Peter.L, V. Kalitzkuz, R. Fisher, and N. Billias (Eds.), Social Studies of Health Illness and Disease;Perspectives from the Social Sciences and Humanities.Amsterdam, New York.175-192.

Hannington, B., and Martin, B. (2012). Universal Methods of Design :100 Ways to Research Complex Problems, Develop Innovative Ideas, and Design Effective Solutions.

(Digital ed.). Beverly, MA:Rockport Publishers. 114.

Haslem, J. (2007). Theraputic Incontinence and Pelvic Pain. Springer 2nd ed, 85.

Haylen, B., Ridde,D., Freeman, R.M.,Swift, S., Berghmans; B., Lee, J., Monga, A., Petri, E., Diaa., Sand, P., Schaer, G.. (2009). An International Urogynecological Association (IUGA)/International Continence Society (ICS) Joint Report on the Terminology for 
A DESIGN ETHNOGRAPHY OF PELVIC FLOOR EXERCISES

Female Pelvic Floor Dysfunction. The International Urogynecological Association. Springer.

Hemmings, T., Crabtree, A., and Rodden, T. (2002). Probing the Probes. In T. Binder, J. Gregory, and I. Wagner. (Ed.), Participatory Design Conference. Malmo Sweden. 42 50.

Healthcare Professionals (2016). Pericoach, Best Kegel Exerciser. Retrieved 09/18/2016 from http://www.pericoach.com.

Highmore, B. (2002). Everyday Life and Cultural Theory. London and New York: Taylor and Francis Group.

Hirsch. T., Forlizzie.J., Hyder. E., Goetz.J., Kurtz., Stroback.J.(2000). The ELDer Project: Social, Emotional, and Environmental Factors in the Design of Eldercare Technologies. Proceedings on the 2000 conference on Universal Usability, 72-79.

Ingber, D. (2003). Mechanobiology and Diseases of Mechanotransduction. . Ann. Med. , 56477.

Kegel, A. (1948). Progressive Resistance Exercise in the Functional Restoration of the Perineal Muscles. Am. J. Obstetrics. Gynecology , 1 (56), 238-248.

Kenton, K. and Mueller, E. R.. (2006). The Global Burden of Female Pelvic Floor Disorders. BJU International, , 98, 1-5.

Kolko, J. (2012). An Introduction to Wicked Problems. In J. Kolko, Wicked Problems, Problems Worth Solving, A Hand Book and a Call to Action. Austin: Austin Center for Design. Retrieved from https://www.wickedproblems.com/read.php

Lagro-Janssen, A. (2012). Women's Perception of Postpartum Pelvic Floor Dysfunction and their Help-seeking Behaviour: a Qualatative Interview Study. Scandinavian Journal of Caring Sciences , 407-413. 
A DESIGN ETHNOGRAPHY OF PELVIC FLOOR EXERCISES

Levin, S. (2002). The Tensegrity-truss as a Model for Spinal Mechanics: Biotensegrity. J. Mechanics of Medical Biology. 375-388.

LOOP. (2015). LOOP. Retrieved 11/ 4/2016, from LOOP: http://loop-health.com/

Malachowski, C. (2015). Organizational Culture Shock: Ethnographic Fieldwork Strategies for the Novice Health Science Researcher. Forum Qualitative Social Research , 16 (2).

Marques, A., Stothers, L., and Macnab, A. (2010). The Status of Pelvic Floor Muscle Training for Women. Canadian Urological Association Journal , 4 (6), 419-424.

Mason, L. R. (2010). The Role of Antenatal Pelvic Floor Muscle Exercises in Prevention of Postpartum Stress Incontinence: a Randomised Controlled Trial. Journal of Clinical Nursing.

Mattelmäki, T. (2005). Applying Probes - from Inspirational Notes to Collaborative Insights. CoDesign: International Journal of CoCreation in Design and the Arts. 1:2.

Mental Health Foundation of New Zealand. (2016). Summer Photo Challenge. Retrieved 17/06/2017 from https://www.facebook.com/mentalhealthfoundationNZ/photos.

Moossdorff-Steinhauser, H.,Albers-Heitner, P., Weemhoff,M., Spaanderman, M., b, Nieman ,F., Berghmans, B.(2015). Factors influencing postpartum women's willingness to participate in a preventive pelvic floor muscle training program: a web-based survey. European Journal of Obstetrics and Gynecology and Reproductive Biology , 182187.

Muratovski,G. (2010). Design and Design Research: The Conflict between the Principles in Design Education and Practices in Industry. Design Principles and Practices, An International Journal , 4 (2), 377-385.

NeuroTrac. (2016). NeuroTrac PelviTone. Retrieved 05 20, 2017, from NeuroTrac : https://veritymedical.co.uk/product/neurotrac-pelvitone/ 
A DESIGN ETHNOGRAPHY OF PELVIC FLOOR EXERCISES

Nova, N. (Ed) (2014). Beyond Design Ethnography, How Designers Practice Ethnogrphic Research. SHS Publishing.

Ovia Health. (NA). Women's and Family Health, Reimagined. Retrieved 2017, from Ovia Health: https://www.ovuline.com/

Park, S. B. (2016). Mobile Health: Empowering pPeople with Type 2 Diabetes Using Digital Tools. News and Media Research Centre, University of Canberra Funded by ACT Government Strategic Opportunities Funding programme .

Parkin, D. (2012). Postpartum Pelvic Floor Dysfunction: Impact Upon Quality of Life, Assessment, Treatment Options in Primary Care and Barriers to Treatment. Journal of the American Academy of Nurse Practitioners , 3-37.

Pelvic Floor Exercise, PFX2. (2017). PFX/PFX2 Plus Free Women's Waterworks. Retrieved 05 20, 2017, from Pelvic Floor Exercise: https://www.pelvicfloorexercise.com.au/shop/womens/pfxpfx2-plus-free-womenswaterworks

Pelvic Floor First. (2016). Pelvic Floor Safe Exercise App . Retrieved 11 04, 2016, from Pelvic Floor First: http://www.pelvicfloorfirst.org.au/pages/pelvic-floor-first-app.html Porrett, T. (2010). Coping and help seeking behaviour in women with Pelvic Floor Dysfunction - the emic perspective. London: City University London. Retrieved from http://openaccess.city.ac.uk/1164/.

Riessman, C. (2001). Analysis of Personal Narratives. (J. G. Holstein., Ed.) Handbook of Interviewing , 1-41.

Rittel, H. and Webber, M. (1973). Dilemmas in a General Theory of Planning. Policy Science , 4. Elsevier Scientific Pubishing Company, Amsterdam. Printed in Scotland. 155169. 
A DESIGN ETHNOGRAPHY OF PELVIC FLOOR EXERCISES

Romano, M., Cacciatore, A., Giordano, R., and La Rosa, B. (2010). Postpartum Period: Three Distinct but Continuous Phases. Journal of Prenatal Medicine, An International Journal of Prenatal Diagnosis and Fetal Maternal Medicine., 22-25.

Rortveit, G., Daltveit, AK., Hannestad,YS., Hunskaar, S. (2003) Urinary Incontinence after Vaginal Delivery or Caesarean Section. New England Journal of Medicine. 348.

Roscam A, E. (2010). In E. Roscam Abbing, Brand Driven Innovation: Strategies for Development and Design. AVA Publishing.80-182.

Saffer, D. (2005). The Role of Metaphor in Interaction Design. Master of Design in Interaction Design., The School of Design Carnegie Mellon University., Interaction Design, Pittsburgh, Pennsylvania.

Savage, J. (2000). Ethnography and Healthcare. BMJ. British Medical Journal Publishing Group. Vol.321 (7273). DOI: 10.1136/bmj.321.7273.

Scholarpedia. (2012). Scholarpedia. (R. b. Buzsaki, Editor) Retrieved 05 03, 2017, from Tensegrity: http://www.scholarpedia.org/article/Tensegrity\#Spanning_the_ArtScience_Interface.

Schutt, R. (2012). Investigating the Social World:The Process and Practice of Research. California: Sage Publications inc.

Shotwell, D. G. (2016). Empowering the Body: The Evolution of Self-help in the Women's Health Movement. 3-263.

Siegel, A. (2016). Our Greatest Wealth is Health. Retrieved 09 04, 2016, from: https://healthdoc13.wordpress.com/2016/04/16/a-brief-history-of-kegel-exercises/.

Sigurdardottir, T., Steingrimsdottir, T., Arnason, A., Bø, K.(2011). Pelvic Floor Muscle Function Before and After First Childbirth. Int. Urogynecology J. , 1497-1503. 
A DESIGN ETHNOGRAPHY OF PELVIC FLOOR EXERCISES

Stevens, P. (1993). Marginalized Women's Access to Healthcare: A Femanist Narrative Analysis. School of Nursing, Mental Health, Community and Administrative Nursing. California, San Francisco: Aspen Publishers inc.

Wherton, J., Sugarhood, P., Procter, R., Rouncefield, M., Dewsbury, G., and Hinder, S. (2012). Designing Assisted Living Technologies 'in the wild': Preliminary Experiences with Cultural Probe Methodology. BMC Medical Research Methodology ,12 (188), 1-13.

Xue, L. (2009). A Female-Focused Design Strategy For Developing a Self-Care Information System. Doctor of Philosophy Thesis , 1-205.

Young, I. M. (2005). Lived Body Vs Gender: Reflections on Social Structure and Subjectivity. In I. M. Young, Studies in Femanist philosophy, On Female Body Experience, 'Throwing like a Girl' and Other Essays (pp. 12-27). New York: Oxford University Press. 